\title{
Determination of interfacial parameters of a soluble particle in a nonideal solution from measured deliquescence and efflorescence humidities
}

\author{
O. Hellmuth ${ }^{1}$ and A. K. Shchekin ${ }^{2}$ \\ ${ }^{1}$ Leibniz Institute for Tropospheric Research (TROPOS), 04318 Leipzig, Germany \\ ${ }^{2}$ St. Petersburg State University, Department of Statistical Physics, 198504 St. Petersburg, Russia
}

Correspondence to: O. Hellmuth (olaf@tropos.de)

Received: 28 May 2014 - Published in Atmos. Chem. Phys. Discuss.: 8 September 2014

Revised: 13 February 2015 - Accepted: 4 March 2015 - Published: 10 April 2015

\begin{abstract}
In order to study the growth/shrinking of a hygroscopic nanoparticle during hydration/dehydration in an atmosphere of water vapour, we have employed a thermodynamic approach proposed by Shchekin et al. (2008). This approach uses the mechanic and thermodynamic concept of disjoining pressure of thin films and allows, among others, the prediction of the humidity growth factor of both (i) a homogeneous solution droplet with completely dissolved residual core and (ii) a heterogeneous solution droplet with partially dissolved residual core as a function of the ambient relative humidity. For application to a nanometric sodium chloride particle we have extended the original approach by (i) considering the nonideality of the solution through the dependence of molecular volumes of the solvent and solute molecules and the solute and solvent activities on the solution concentration, (ii) deriving an equation for the estimation of the efflorescence properties of a homogeneous solution droplet, and (iii) combining the empirical power law fittings for the size dependence of the deliquescence and efflorescence relative humidity values by Biskos et al. (2006a). It was demonstrated how the solution/solute interface energy and the correlation length of a thin solution film can be determined from a combination of experimentally determinable efflorescence and deliquescence humidities with the present calculus. The solution/solute interface energy was found to be in close agreement with some previous values reported in the literature, while it strongly differs from data of some other sources. The calculated deliquescence humidity shows a low sensitivity to the choice of the numerical value for the film correlation length. The estimated film correlation length of $1 \mathrm{~nm}$ for a nanometric sodium chloride particle with dry particle
\end{abstract}

radius of $5 \mathrm{~nm}$ was found to be reconcilable with available a priori estimates of the correlation length from the literature when the measurement uncertainty of the deliquescence humidity is considered. Considering the combination of an extensive calculus, a comprehensive set of thermophysical constraints, and independent measurements of the deliquescence and efflorescence humidities as functions of dry particle radius, the obtained values of the solution/solute interface energy and the correlation length are in close agreement with previous estimations. The humidification of sodium chloride particles in the initial hydration stages was found to be very sensitive to the specification of the disjoining pressure. The enhancement of the wettability of the particle surface leads to an earlier onset of hygroscopic growth.

\section{Introduction}

The importance of deliquescence and efflorescence (the notions of which will be explained below) for atmospheric models and processes, especially for climate models, originates from associated radiative effects (see Anonymous Referee, 2014, and references given therein to e.g. Cziczo and Abbatt, 1999, Oatis et al., 1998, Xu et al., 1998, Lohmann and Feichter, 2005, Khvorostyanov and Curry, 2014, Sects. 2.3, 2.5, 6.1, 11.1 therein). Deliquescence and efflorescence of aerosols impact the aerosol optical thickness and, in this way, the direct aerosol effect. It also influences activation of cloud condensation nuclei (CCN) into cloud drops and determines the first and second indirect aerosol 
effects via cloud drops and, after subsequent freezing, several other indirect aerosol effects. Activated drops participate in cloud dynamical circulation. Due to downdrafts near the cloud edges, such drops can be transported below the cloud bottom, where they may penetrate into the very dry environment (something similar can happen due to lateral entrainment of dry environmental air into cloudy air). Such drying may cause the reverse effect: evaporation of the drops to the sizes of CCN with strongly supersaturated solution concentration, which may in turn cause efflorescence and transformation of the aerosol particles to the state close to the original dry or slightly wetted CCN. When such particles are brought again into the cloud by the updrafts they can grow again, may be activated, and may influence cloud microphysical and optical properties. Accounting for the significant variability of aerosol over the globe, it is obvious that any reliable estimates of aerosol impacts on clouds and climate change require physically appropriate theories of aerosol deliquescence and efflorescence.

Soluble substances (mostly salts) have a strong affinity for moisture i.e. they are able to absorb water molecules from the ambient air. When the ambient relative humidity ( $\mathrm{RH})$ is sufficiently high, the water uptake continues until the hygroscopic particle completely dissolves in the absorbed water, in this way forming a pure solution droplet. The transition from partial to complete dissolution is called deliquescence, and the RH threshold at which a soluble particle completely dissolves is called deliquescence humidity (DRH). For highly soluble salts such as sodium chloride $(\mathrm{NaCl})$ and small condensation nuclei, deliquescence occurs at subsaturation of the ambient partial water vapour with respect to a flat surface of pure bulk water ( $\mathrm{RH}<100 \%$ rh). In the case of low soluble and larger nuclei, deliquescence can also occur in supersaturated vapour.

The reverse process, called efflorescence (or crystallisation), leads to hydrosol formation by precipitation of solid crystals from the solution within existing droplets. Crystallisation proceeds via two steps: (i) nucleation and (ii) crystal growth. In the nucleation step, solute molecules, dispersed in the solvent, start to form clusters on the nanometre scale. These clusters need to reach a critical size (embryonic stage) in order to freely grow to solid precipitates within the maternal solution droplet. The critical size of the embryo depends on temperature, supersaturation, and the droplet size. The crystallisation is driven by the supersaturation of the solution, which depends on both ambient relative humidity and temperature. The relative humidity at which efflorescence sets in is called efflorescence humidity (ERH). The difference between DRH and ERH results in a hysteresis effect. Owing to the high variability of the relative humidity and temperature in the ambient atmosphere e.g. due to multiscale turbulence, hysteresis effects effectively impact the partitioning between solid and aqueous phases of tropospheric $\mathrm{NaCl}$ and $\left(\mathrm{NH}_{4}\right)_{2} \mathrm{SO}_{4}$ particles. In ambient air, hygroscopic particles may exist in homogeneous and heterogeneous states.
The homogeneous state can be either a pure solid core or a pure solution droplet. The heterogeneous state is a thermodynamically stable configuration in which a solid core substrate may coexist in thermodynamic equilibrium with an enveloping aqueous solution. The solid core can either consist of completely soluble matter or be a mixture of some insoluble fraction, coated with a soluble mantle of certain thickness. Here, we want to restrict our consideration to soluble one-component solid cores.

The atmospheric impact of hygroscopic particles is threefold:

- Hygroscopic particles may impact the global energy balance by its cooling effect (Wise et al., 2012, see references therein for the role of sea salt aerosol). The radiative properties of such particles depend on the liquid/solid phase partitioning within the particles (Wang et al., 2008a, 2008b), among others. Aqueous particles have a larger mass extinction efficiency but a smaller backscattered fraction than their solid counterparts. Owing to the high variability of the relative humidity in the planetary boundary layer, hysteresis effects were found to effectively impact the partitioning between solid and aqueous phases of tropospheric salts on a global scale. For ammonium-sulfate particles, Wang et al. (2008a) reported a significant impact of the solid/liquid phase partitioning on the sulfate direct climate forcing (SDFC). Depending on how these effects were parameterised in a global 3-D chemical transport model, an uncertainty in the SDFC of $23 \%$ on the global scale (but of much higher values on regional scales) has been found from sensitivity studies (Wang et al., 2008b).

- Sea salt aerosol (SSA) is a major contributor to natural global aerosol emission and a main source of hygroscopic particles. According to Seinfeld and Pandis (2006, see p. 61, Table 2.22 therein $)^{1}$ the best estimate of the SSA emission flux amounts $10100 \mathrm{Tg} \mathrm{yr}^{-1}$. This is nearly 40 fold of the best estimate of the total (primary plus secondary) anthropogenic aerosol flux $\left(\approx 263 \mathrm{Tg} \mathrm{yr}^{-1}\right)$, and $75 \%$ of the best estimate of the total (natural plus anthropogenic) aerosol flux $(\approx$ $13466 \mathrm{Tg} \mathrm{yr}^{-1}$ ). Natural SSA particles have a complex chemical composition. As many physical properties of SSA are controlled by $\mathrm{NaCl}$ (e.g. light scattering efficiency), several authors, e.g. Wise et al. (2012, see references therein), use $\mathrm{NaCl}$ as a proxy for $\mathrm{SSA}^{2}$.

\footnotetext{
${ }^{1}$ In the cited table only the global emission estimates for the major aerosol classes have been considered.

${ }^{2}$ The mining of salt in Europe can be traced back to about 4000 years ago (Schmiedel, 1984). Justus von Liebig characterised salt as the most valuable among all precious stones, and Cassiodor, roman statesman (6th century), stated that gold is dispensable but salt is not (Bontjer, 2014). In the middle ages salt was called "white gold". Despite of its importance in daily life, environmental science,
} 
- Hygroscopic particles from SSA may serve as ice nuclei and influence cirrus formation. The mechanism of deliquescent-homogeneous and heterogeneous freezing and its atmospheric relevance has been intensively studied by Khvorostyanov and Sassen (1998a, b, 2002); Khvorostyanov and Curry (2000, 2004a, b, 2005, 2007, 2009, 2012, 2014); Khvorostyanov et al. (2001, 2003, 2006), and Curry and Khvorostyanov (2012). Recently, also efflorescent-heterogeneous nucleation onto SSA particles has attracted increasingly interest (Wise et al., 2012; Wagner and Möhler, 2013). Investigating the freezing capability of SSA particles, Wise et al. (2012) pointed out the temperature dependence of phase composition of SSA particles: a brine solution and solid sodium chloride dihydrate $\left(\mathrm{NaCl} \cdot 2 \mathrm{H}_{2} \mathrm{O}(\mathrm{s})\right)$ are stable from the triple point of water to the eutectic temperature $^{3}$. Below the eutectic temperature, solid ice and sodium chloride dihydrate are stable. The authors found the following efflorescence behaviour of aqueous $\mathrm{NaCl}$ particles: (i) at temperatures above the eutectic temperature, solution particles effloresced into anhydrous solid $\mathrm{NaCl}$ particles; (ii) at temperatures below the eutectic temperature but above $236 \mathrm{~K}$, solution drops effloresced to a mixture of anhydrous and hydrated solid particles; (iii) at temperatures below $236 \mathrm{~K}$, solution drops effloresced into hydrated solid particles. Wise et al. demonstrated the high efficiency of depositional ice nucleation on both crystalline anhydrous and hydrated $\mathrm{NaCl}$ particles, with an even better ice nucleation capability of hydrated particles. The authors referred to field observations of the chemical composition of anvil cirrus residue near the Florida peninsula, which revealed a SSA fraction of anvil ice residue of $26 \%$. In the present case, however, we will restrict our consideration to a temperature well above the eutectic temperature; i.e. "eutectic solidification" will be excluded.

biophysics, catalysis etc., many fundamental physical and chemical properties of $\mathrm{NaCl}$ surfaces are still unknown and deserve a better understanding (Li, 2009, see Chap. 3 therein).

${ }^{3}$ The eutecticum or "eutectic mixture" of chemical compounds or elements denotes the solidification products of homogeneous mixed melts at that chemical composition at which the melting point is lower than at any other chemical composition made up of the same ingredients (Wolf, 1959, p. 763 therein). Similarly, Atkins (1994, 254-255 therein) wrote that a liquid with eutectic composition freezes at a single temperature, without previously depositing solid A or B. A solid with the eutectic composition melts, without change of composition, at the lowest temperature of any mixture (see also Wedler, 2004, pp. 364-365 therein). The composition of the eutecticum is known as the eutectic composition and the temperature at which it solidifies is known as the eutectic temperature. The name eutectic composition comes from Greek words for "easily melted" (Atkins, 1994, p. 254 therein). Water and sodium chloride form a eutectic mixture. The eutectic temperature of aqueous sodium chloride solution is $\vartheta_{\mathrm{E}}=-21.2^{\circ} \mathrm{C}$; the eutectic mass fraction of solute is 0.2242 (Brdička, 1965, p. 513 therein).
- Hygroscopic particles may act as chemical microreactors for hydrolysis, secondary organic aerosol formation, micellisation, and heterogeneous surface reactions.

From evaluation of 9 years of radiosonde observations at five stations representing oceanic conditions (years 1980 1988 , latitude from $14.3^{\circ} \mathrm{S}-57.2^{\circ} \mathrm{N}$ ), Liu et al. (1991, Fig. 2 therein) derived vertical profiles of the 9-year means of the relative humidity (inclusive standard deviations of individual measurements and standard deviations of the monthly means). These data reveal some common features of the humidity profile at all stations. The $\mathrm{RH}$ surface values were reported to vary between the stations in the range $\overline{\mathrm{RH}}_{0} \approx 75$ $82 \%$ rh. The humidity profiles revealed their maximum values (spatially varying in the range $\overline{\mathrm{RH}}_{\max } \approx 84-90 \%$ rh) just below the height of the $900 \mathrm{hPa}$ surface. From the level of RH maxima, the mean relative humidity decreased to minimum values (spatially varying in the range $\overline{\mathrm{RH}}_{\text {min }} \approx 30-40 \%$ rh) in the upper troposphere. These observations revealed that the vertical variation of the tropospheric relative humidity over the ocean safely exceeds the humidity interval fixed by the deliquescence and efflorescence humidities of sodium chloride particles (Seinfeld and Pandis, 2006, see Sect. 10.2 therein; Biskos et al., 2006b). Thus, in the marine troposphere sodium chloride particles are expected to exist both in homogeneous (either as an aqueous solution or as pure solid) and in heterogeneous (a solid core enveloped by a liquid solution film) states depending on the particle size.

The study of the deliquescence behaviour of hygroscopic particles in the limit of bulk properties is well understood (Seinfeld and Pandis, 2006, see e.g. Sect. 10.2 therein). In contrast to this, the investigation of size-dependent effects in both deliquescence and efflorescence is comparatively rare and not completely understood so far.

McGraw and Lewis (2009) investigated the sizedependent deliquescence/efflorescence phase transformation for particles down to several nanometres in size. The authors analysed the thermodynamic properties of inorganic salt particles coated with aqueous solution layers of varying thickness and surrounded by vapour. In order to define a limiting deliquescence relative humidity $\left(\mathrm{RH}_{\mathrm{D}}\right)$ for small particles a thin layer criterion (TLC) has been introduced, which is based on the fulfillment of two equilibrium conditions: (1) equality of chemical potentials between salt in an undissolved core and thin adsorbed solution layer, and (2) equality of chemical potentials between water in the thin layer and vapour phase. For the limit of large dry particle size, the bulk deliquescence properties were obtained. Nanosized particles were reported to deliquesce at relative humidity just below the $\mathrm{RH}_{\mathrm{D}}$, crossing a nucleation barrier located at a critical solution layer thickness. This nucleation barrier will vanish at the $\mathrm{RH}_{\mathrm{D}}$ defined by the TLC. The authors employed concepts and methods from nucleation theory including the kinetic potential, self-consistent nucleation theory, nucleation theorems, and the Gibbs dividing surface, altogether provid- 
ing the theoretical foundation of their approach. McGraw and Lewis (2009) emphasised the existence of unifying features of small particle deliquescence/efflorescence processes such as common thermodynamic area constructions and a common free-energy surface. However, the approach of McGraw and Lewis (2009) is based on the employment of the classical capillary drop model but does not explicitly consider measurable thin film quantities such as the disjoining pressure, which is indispensable for the description of the initial stages of hygroscopic growth from the formation of first monolayers up to thick films. Here, we can already antedate that the approach of McGraw and Lewis (2009) and the one presented in this paper essentially differ in the way of "metrisation" of the small particle deliquescence/efflorescence processes leading to complementary information about these processes.

Bruzewicz et al. (2011) characterised the behaviour of $\mathrm{NaCl}$ nanoparticles as a function of RH. The authors measured the heights of particles deposited on a prepared hydrophobic surface by means of non-contact environmental atomic force microscopy and found a cubic shape of $\mathrm{NaCl}$ nanoparticles with sides of 35 and $80 \mathrm{~nm}$. These nanoparticles were observed to reversibly take up water with increasing RH well below the bulk DRH of $75 \%$ rh at $23^{\circ} \mathrm{C}$, forming of a liquid-like surface layer of thickness 2 to $5 \mathrm{~nm}$ with measurable uptake ( $>2 \mathrm{~nm}$ increase in particle height) beginning at $70 \%$ rh. The maximum thickness of the layer was observed to increase with increasing $\mathrm{RH}$ and increasing particle size over the investigated size range. The liquid-like layer appeared as a reversible rounding at the upper surface of the particles with the shape of the layer fitting to a parabolic cross section. The ratio of particle height to maximum radius of curvature was reported to increase from 0 (flat top) at $68 \%$ rh to $0.7 \pm 0.3$ at $74 \%$ rh. From their observations, Bruzewicz et al. (2011) concluded the occurrence of mass reorganisation on the solid $\mathrm{NaCl}$ nanocrystal at $\mathrm{RH}$ below the $\mathrm{DRH}$, suggesting that the deliquescence of $\mathrm{NaCl}$ nanoparticles "is more complex than an abrupt first-order phase transition". The height measurements were found to be consistent with a phenomenological model that assumes favourable contributions to the free energy of formation of a liquid layer on solid $\mathrm{NaCl}$ due to both van der Waals interactions (depending partly upon the Hamaker constant of the interaction between the thin liquid film and the solid $\mathrm{NaCl}$ ), and to a longer-range electrostatic interaction over a characteristic length of persistence. The authors derived best-fit values for the Hamaker constant and the persistence length scale.

Using the thermodynamic theory of thin solution films developed by Shchekin et al. (1993), Kuni et al. (2001), Djikaev et al. (2001a), Djikaev et al. (2001b) and Djikaev (2002) based on the mechanical and thermodynamic concept of the disjoining pressure, Shchekin and Shabaev (2005), Shchekin and Rusanov (2008) and Shchekin et al. (2008) derived, for the limit of ideality of the aqueous electrolyte solution, generalisations of the Gibbs-Kelvin-Köhler (GKK) equation of the theory of nucleation on soluble particles and of the Ostwald-Freundlich (OF) equation of the theory of solutions (hereafter called SSR theory according to the initials of the authors Shchekin, Shabaev, and Rusanov). These equations allow (i) the determination of the humidity growth factor of a hygroscopic particle ${ }^{4}$ as a function of ambient temperature, relative humidity, dry particle radius, and of different thermophysical and interfacial parameters of the system and (ii) the determination of the DRH.

Based on the SSR theory, the present study pursues the following aims:

1. First, the generalised GKK and OF equations as predicted by the SSR theory will be extended to determine the humidity growth factor and DRH also for nonideal aqueous solutions.

2. In contrast to the DRH determination, the ERH cannot be obtained from a pure thermodynamic approach alone but also requires a kinetic consideration (e.g. Onasch et al., 2000, Pant et al., 2006, Parsons et al., 2006, Shchekin and Shabaev, 20105, and Shchekin et al., 2013). Second, therefore, a governing equation for determination of the ERH on the base of the classical nucleation theory (CNT), applied to homogeneous salt crystallisation from a supersaturated solution, will be derived.

3. Third, it will be demonstrated how the extended SSR theory in combination with CNT can be used to determine the specific interfacial parameters, namely the solution/salt interfacial energy, and the characteristic correlation length of a thin film, which are difficult to obtain from direct measurements. In the present approach the mentioned interfacial parameters will be estimated by considering size-dependent DRH and ERH values obtainable from measurements.

4. Fourth, by application of the calculus to a nanometric $\mathrm{NaCl}$ particle in a water vapour environment we will show that the approach presented here is able to theoretically describe the phenomenon observed by Bruzewicz et al. (2011) at least in a qualitative way.

The paper is structured as follows. In Sect. 2 we will briefly describe the model; in Sect. 3 we will present the method for the estimation of interfacial properties; in Sect. 4 we will present and discuss the model results, and the last section

\footnotetext{
${ }^{4}$ The humidity growth factor is defined as the ratio of the radius of the hygroscopic particle to the dry particle radius.

${ }^{5}$ Shchekin and Shabaev extended their approach to the determination of the activation barriers for the complete dissolution of a condensation nucleus and its reverse crystallisation in droplets in a subsaturated solvent vapour between DRH and ERH. The authors showed that the coexistence of drops with partly and completely dissolved nuclei is impossible.
} 
contains the summary and conclusions. A comprehensive detailed outline of the calculus can be found in the Supplement.

\section{Model description}

\subsection{Determination of humidity growth factor and the deliquescence humidity according to SSR theory}

\subsubsection{Governing equations}

The basic scenario and assumptions are described in Sect. S1.1 in the Supplement. In the initial state, the system consists of a soluble solid core (phase $\gamma$ ) with dry particle radius $R_{\mathrm{N}}$, embedded in a solvent vapour (phase $\beta$ ) within fixed volume $V$ at absolute temperature $T$. In the final state, a liquid droplet (phase $\alpha$ ) of radius $R$ is formed including, depending on the ambient $\mathrm{RH}$, either a partially dissolved residual core of radius $R_{\mathrm{N}}^{\prime}$ enveloped by a liquid film of thickness $h=R-R_{\mathrm{N}}^{\prime}$ (phase $\alpha$ ) or the residual core being completely dissolved, $R_{\mathrm{N}}^{\prime}=0$. The formation work $\Delta F$, required to form a heterogeneous droplet from a vapour, reads (see Sect. S1.3, Eq. (S43) in the Supplement)

$$
\begin{aligned}
& \Delta F=-\Delta N^{(\beta \rightarrow \alpha)}\left[\mu^{(\beta)}-\mu_{\star}^{(\beta \rightarrow \alpha)}\right]+\Delta N^{(\gamma \rightarrow \alpha)}\left[\mu_{\star}^{(\gamma \rightarrow \alpha)}-\mu_{\infty}^{(\gamma)}\right] \\
& +4 \pi R^{2} \sigma_{\infty}^{(\alpha \beta)}+\Delta F_{\mathrm{W}}, \\
& \Delta F_{\mathrm{W}}=4 \pi R_{\mathrm{N}}^{\prime 2}\left[\sigma_{\infty}^{(\alpha \gamma)}+l^{(\star)} \Pi_{\mathrm{D}}(h)\right]-4 \pi R_{\mathrm{N}}^{2} \sigma_{\infty}^{(\beta \gamma)}, \\
& \mu_{\star}^{(\beta \rightarrow \alpha)}(x)=\mu_{\infty}^{(\beta)}+k_{\mathrm{B}} T \ln \left[\frac{a_{\text {solvent }}(x)}{a_{\text {solvent }}(x=0)}\right], \\
& \mu_{\star}^{(\gamma \rightarrow \alpha)}(x)=\mu_{\infty}^{(\gamma)}+k_{\mathrm{B}} T \ln \left[\frac{a_{\text {solute }}(x)}{a_{\text {solute }}\left(x_{\infty}\right)}\right] .
\end{aligned}
$$

Here, $\Delta N^{(\beta \rightarrow \alpha)}$ denotes the number of solvent molecules condensed from the vapour into the solution film, and $\Delta N^{(\beta \rightarrow \alpha)}$ is the number of solute molecules dissolved from the solute into the solution film. The quantity $\mu^{(\beta)}\left(T, S^{(\beta)}\right)$ is the chemical potential of the solvent vapour, which is a function of temperature and vapour saturation ratio $S^{(\beta)}$; $\mu_{\infty}^{(\beta)}$ is the value of $\mu^{(\beta)}$ at equilibrium of the vapour with a pure bulk liquid. The chemical potential differences $\mu_{\star}^{(\beta \rightarrow \alpha)}(x)-\mu_{\infty}^{(\beta)}$ and $\mu_{\star}^{(\gamma \rightarrow \alpha)}(x)-\mu_{\infty}^{(\gamma)}$ represent the activity contributions to the chemical potentials of solvent and solute molecules in the solutions $\mu^{(\beta \rightarrow \alpha)}$ and $\mu^{(\gamma \rightarrow \alpha)}$ respectively, and $\mu_{\infty}^{(\gamma)}$ is the equilibrium value of the chemical potential of the solid matter at the flat interface between the solid substrate and a bulk solution at saturation vapour pressure. The quantity $a_{\text {solvent }}(x)$ is the solvent (water) activity as a function of the relative solute concentration $x=m M_{\mathrm{W}} /\left(1+m M_{\mathrm{W}}\right)$ in the film, with $m$ denoting the molality of the solution and $M_{\mathrm{W}}$ the molar mass of water. Analogously, $a_{\text {solute }}(x)$ is the solute (salt) activity as a function of the relative solute concentration in the film, and $x_{\infty}$ is the relative solute concentration corresponding to the solubility of the solute.
The term $\Delta F_{\mathrm{W}}$ in Eq. (1) represents the work of wetting of a soluble nucleus. The derivation of this term is based on the negligence of adsorption of salt at the droplet surface. Furthermore, all surface tensions and parameters of the disjoining pressure have been taken as independent of salt concentration. The function $\Pi_{\mathrm{D}}(h)=K^{(\star)} \exp \left(-h / l^{(\star)}\right)$ appearing in the term $\Delta F_{\mathrm{W}}$ is the disjoining pressure of a thin solution film, with $K^{(\star)}=s / l^{(\star)}$ denoting a characteristic pressure scale of the thin film. The quantity $s=\sigma_{\infty}^{(\beta \gamma)}$ $\left(\sigma_{\infty}^{(\alpha \beta)}+\sigma_{\infty}^{(\alpha \gamma)}\right)$ therein is the nonequilibrium spreading coefficient with $\sigma_{\infty}^{(\alpha \beta)}, \sigma_{\infty}^{(\alpha \gamma)}$, and $\sigma_{\infty}^{(\beta \gamma)}$ denoting the surface tension of the bulk solution (in the absence of vapour adsorption), the solution/solute, and vapour/solute interfacial energies respectively (Shchekin et al., 2008, Eqs. (28) and (29) therein). The quantity $l^{(\star)}$ is the film correlation length, which is of the order of the intermolecular separation in the film (Rusanov et al., 1994). Furthermore, $k_{\mathrm{B}}$ denotes the Boltzmann constant.

The disjoining pressure of a thin liquid film is the excess free energy density (free energy per unit volume), which originates from the overlapping of molecular interactions at both sides of the film when the film thickness decreases down to nanometric scales and the interfaces approach each other. It arises together with the nonuniformity of the middle part of the film. While the surface tension of a "thick" film (considered as a "bulk" liquid phase) is given by the sum of the surface tensions of both adjacent film interfaces, the principle of additivity of surface tensions cannot be applied any longer to a "thin" film. Upon thinning a liquid film, the interfacial layers on both sides of the film start to penetrate each other, leading to the emergence of an extra excess value which must be additionally considered in the calculation of the film surface tension. The disjoining pressure decreases upon increasing the film thickness and can be neglected in the limiting case of a thick film. The value of the disjoining pressure results from a superposition of contributions from different kinds of molecular interactions. The strengths of these interactions depend on the physical properties of the film phase and the ambient phases adjacent to the film. The shape of the functional dependence of the disjoining pressures on the film thickness results from molecular theory; the quantification of the disjoining pressure values requires experimental data and/or computer simulations. The notion "disjoining pressure" (German: "Spaltdruck") was introduced by B. V. Derjaguin (e.g. Derjaguin, 1955a, b; Derjaguin et al., 1987) to characterise the interaction-induced excess pressure appearing in a "join". The disjoining pressure is a signed value; i.e. it can effectively act as a "disjoining pressure" (due to repelling forces) or as a "joining pressure" (due to attractive forces). Details of the physical motivation of the concept of disjoining pressure and references for the specification applied here can be found in Sects. S.1.2 and S.1.7 in the Supplement. 
The equilibrium state of the droplet is controlled by two thermodynamic conditions corresponding to the locations of the minima and saddle points of the formation work (see Sect. S1.4 in the Supplement):

- the "external solvent equilibrium" between the solvent in the vapour phase $\beta$ and the solvent in the liquid phase $\alpha$

- the "internal solute equilibrium" between the solute in the residual solid phase $\gamma^{\prime}$ and the solute in the liquid phase $\alpha$.

At external equilibrium, the thermodynamic driving force for the transfer of solvent molecules from the vapour phase into the liquid phase must vanish. From this condition one can arrive at the following generalisation of the Gibbs-KelvinKöhler equation of the theory of nucleation on soluble particles (see Sect. S1.4 and Eq. (S54) in the Supplement):

$$
\begin{aligned}
& \left.\mathcal{F}_{\mathrm{GKK}}\left(S^{(\beta)}, R_{\mathrm{N}}^{\prime}, R\right)\right|_{\substack{T=\text { const } \\
R_{\mathrm{N}}=\text { const }}}=-k_{\mathrm{B}} T \ln S^{(\beta)} \\
& +k_{\mathrm{B}} T \ln \left[\frac{a_{\text {solvent }}\left(x\left(R, R_{\mathrm{N}}^{\prime}\right)\right)}{a_{\text {solvent }}(0)}\right] \\
& +v^{(\beta \rightarrow \alpha)}(x)\left[\frac{2 \sigma_{\infty}^{(\alpha \beta)}}{R}-\left(\frac{R_{\mathrm{N}}^{\prime}}{R}\right)^{2} \Pi_{\mathrm{D}}(h)\right]=0 .
\end{aligned}
$$

In Eq. (2), $S^{(\beta)}$ denotes the ratio of the actual water vapour pressure to the saturated water vapour pressure over bulk water (hereafter called the water vapour saturation ratio in accordance with Seinfeld and Pandis, 2006, p. 813 therein), and $v^{(\beta \rightarrow \alpha)}(x)$ is the partial molecular volume of solvent molecules in the solution.

At internal equilibrium, the thermodynamic driving force for the transfer of solute molecules from the solid phase into the liquid phase must vanish. This leads to the following generalisation of the Ostwald-Freundlich equation of the theory of solutions (see Sect. S1.4 and Eq. (S56) in the Supplement):

$$
\begin{aligned}
& \left.\mathcal{F}_{\mathrm{OF}}\left(R_{\mathrm{N}}^{\prime}, R\right)\right|_{\substack{T=\text { const } \\
R_{\mathrm{N}}=\text { const }}}=k_{\mathrm{B}} T \ln \left[\frac{a_{\text {solute }}\left(x\left(R, R_{\mathrm{N}}^{\prime}\right)\right)}{a_{\text {solute }}\left(x_{\infty}\right)}\right] \\
& +v^{(\gamma \rightarrow \alpha)}(x)\left[\frac{2 \sigma_{\infty}^{(\alpha \beta)}}{R}-\left(\frac{R_{\mathrm{N}}^{\prime}}{R}\right)^{2} \Pi_{\mathrm{D}}(h)\right] \\
& -v^{(\gamma)}\left[\frac{2 \sigma_{\infty}^{(\alpha \beta)}}{R}-\left(\frac{R_{\mathrm{N}}^{\prime}}{R}\right)^{2} \Pi_{\mathrm{D}}(h)+\frac{2 \sigma_{\infty}^{(\alpha \gamma)}}{R_{\mathrm{N}}^{\prime}}\right. \\
& \left.+\left(1+\frac{2 l^{(\star)}}{R_{\mathrm{N}}^{\prime}}\right) \Pi_{\mathrm{D}}(h)\right]=0 .
\end{aligned}
$$

In Eq. (3), $v^{(\gamma)}$ and $v^{(\gamma \rightarrow \alpha)}(x)$ are the partial molecular volumes of solute molecules in the solid phase and of dissolved solute molecules in the solution film respectively.

Equations (2) and (3) are extensions of the generalised GKK and OF equations as derived by Shchekin et al. (2008,
Eqs. (25) and (26) therein) for the limit of an ideal solution ${ }^{6}$ and serve as governing equations for determination of the humidity growth factor and DRH.

\subsubsection{Determination of the humidity growth factor}

As demonstrated by Shchekin et al. (2008, see Sect. V, Fig. 6 therein), the dependence of the droplet radius $R$ on the vapour saturation ratio $S^{(\beta)}$ at equilibrium between the droplet and the ambient vapour can be fully determined from simultaneous solution of the generalised GKK and OF Eqs. (2) and (3) (see Sect. S1.5 in the Supplement). Knowing the relation $R=f\left(T, R_{\mathrm{N}}, S^{(\beta)}\right)$, the measurable vapour condensation growth factor GF can be directly determined:

$\mathrm{GF}=\frac{R}{R_{\mathrm{N}}}=R_{\mathrm{N}}^{-1} f\left(T, R_{\mathrm{N}}, S^{(\beta)}\right)$.

\subsubsection{Determination of the deliquescence humidity}

Prompt transition from the equilibrium state with the partially dissolved residual core to the equilibrium state with the completely dissolved residual core ("deliquescence transition") is a barrierless process. As demonstrated by Shchekin et al. (2008, see Sect. V, Figs. 4-6 therein), the determination of the vapour saturation ratio at deliquescence, $S_{\mathrm{th}}^{(\beta)}=$ $\mathrm{DRH} / 100 \%$, proceeds as follows (see Sect. S1.6 in the Supplement).

Firstly, the drop radius is determined as a function of the residual radius $R=R\left(R_{\mathrm{N}}^{\prime}\right)$ from the numerical solution of the transcendental OF Eq. (3).

Secondly, we employ the expression for the chemical potential of solvent molecules in the liquid film given in thermal units, $b^{(\beta \rightarrow \alpha)}$ (see Sect. S1.6 and Eq. (S62) in the Supplement):

\footnotetext{
${ }^{6}$ In derivation of their generalised GKK Eq. (25), Shchekin et al. (2008) employed the approximations $a_{\text {solvent }}(x) \approx 1-x$, (with the Taylor expansion $\left.\ln a_{\text {solvent }}(x) \approx-x\right)$ and $a_{\text {solute }}(x) \approx x$ for the limit of an ideal solution. Furthermore, the molality-dependent partial molecular volume of solvent molecules in the solution, $v^{(\beta \rightarrow \alpha)}(x)$, has been approximated by an average value for the molecular volume of solution molecules in the solution, $\bar{v}^{(\alpha)}$. Analogously, in derivation of their generalised OF Eq. (26), the authors employed the ideal-solution limit $a_{\text {solute }}(x) \approx x$ and approximated the molality-dependent partial molecular volume of solute molecules in the solution, $v^{(\gamma \rightarrow \alpha)}(x)$, by an average value $\bar{v}^{(\gamma \rightarrow \alpha)}$. Note that Eqs. (25) and (26) of Shchekin et al. (2008) can be obtained as special cases of Eqs. (2) and (3), but, vice versa, the latter cannot be obtained by formal replacement of quantities referring to the ideal-solution limit in Eqs. (25) and (26) of Shchekin et al. (2008).
} 


$$
\begin{aligned}
& b^{(\beta \rightarrow \alpha)}\left(R, R_{\mathrm{N}}^{\prime}\right)=\frac{\mu^{(\beta \rightarrow \alpha)}-\mu_{\infty}^{(\beta)}}{k_{\mathrm{B}} T} \\
& =\ln \left[\frac{a_{\text {Solvent }}\left(x\left(R, R_{\mathrm{N}}^{\prime}\right)\right)}{a_{\text {solvent }}(0)}\right]+\frac{v^{(\beta \rightarrow \alpha)}\left(x\left(R, R_{\mathrm{N}}^{\prime}\right)\right)}{k_{\mathrm{B}} T} \\
& \times\left[\frac{2 \sigma_{\infty}^{(\alpha \beta)}}{R}-\left(\frac{R_{\mathrm{N}}^{\prime}}{R}\right)^{2} \Pi_{\mathrm{D}}\left(h\left(R, R_{\mathrm{N}}^{\prime}\right)\right)\right] .
\end{aligned}
$$

Here, $\mu^{(\beta \rightarrow \alpha)}$ and $\mu_{\infty}^{(\beta)}$ are the chemical potentials of the solvent molecules in the liquid film and of the vapour at equilibrium with a pure bulk liquid having a flat interface. Inserting function $R_{\mathrm{N}}^{\prime}=R_{\mathrm{N}}^{\prime}(R)$ into Eq. (5) delivers the chemical potential of solvent molecules in the solution as a function of drop radius, $b^{(\beta \rightarrow \alpha)}=b^{(\beta \rightarrow \alpha)}(R)$.

Thirdly, from $b^{(\beta \rightarrow \alpha)}=b^{(\beta \rightarrow \alpha)}(R)$ the maximum value $b_{\mathrm{th}}^{(\beta \rightarrow \alpha)}$ is determined, which allows us to find the deliquescence vapour saturation ratio according to $S_{\mathrm{th}}^{(\beta)}=$ $\exp \left(b_{\mathrm{th}}^{(\beta \rightarrow \alpha)}\right)$ and the deliquescence relative humidity defined by DRH $=100 \% \times S_{\text {th }}^{(\beta)}$.

\subsection{Determination of the efflorescence humidity according to CNT}

The prompt transition from a homogeneous solution droplet to a solution droplet with a stable crystal core is called efflorescence transition. It performs via homogeneous crystallisation i.e. precipitation of solute crystals from a supersaturated solution droplet. Supersaturation of the solution can be achieved by decreasing the chemical potential of the solvent vapour (or by decreasing the temperature). Here, for a confined system such as a submicron droplet, the efflorescence is assumed to be the result of only one successful crystallisation event inside the solution droplet.

Based on the classical nucleation theory (here homogeneous nucleation) and the efflorescence condition employed by e.g. Gao et al. (2007), Onasch et al. (2000), Pant et al. (2006), and Parsons et al. (2006), one can derive the following governing equation for the determination of the relative solute concentration of a solution droplet with completely dissolved residual core $\left(R_{\mathrm{N}}^{\prime}=0\right)$ at efflorescence transition, $x_{\text {effl }}=x(\mathrm{ERH})$ (see Sect. S2., Eqs. (S81) and (S82) in the Supplement):

$$
\begin{aligned}
& \mathcal{F}_{\mathrm{CNT}}\left(R\left(x_{\mathrm{eff}}\right)\right) \mid \begin{array}{l}
T=\text { const } \\
R_{\mathrm{N}}^{\prime}=0 \\
R_{\mathrm{N}}=\text { const }
\end{array} \\
& =\left\{\frac{16 \pi}{3}\left[\frac{\sigma_{\infty}^{(\alpha \gamma)}}{k_{\mathrm{B}} T}\right]^{3} \frac{\left[v^{(\gamma)}\right]^{2}}{\ln \left[\frac{4}{3} \pi\left[R\left(x_{\mathrm{eff}}\right)\right]^{3} J_{\mathrm{hom}, 0} \tau_{\mathrm{ind}}\right]}\right\}^{1 / 2} \\
& -\ln \left[\frac{a_{\text {solute }}\left(x_{\text {effl }}\right)}{a_{\text {solute }}\left(x_{\infty}\right)}\right]=0, \\
& J_{\text {hom }, 0}=\left[v^{(\gamma)}\right]^{-1}\left(\frac{k_{\mathrm{B}} T}{h}\right) \exp \left(-\frac{\Delta F_{\text {act }}}{k_{\mathrm{B}} T}\right) .
\end{aligned}
$$

In Eq. (6), $J_{\mathrm{hom}, 0}$ denotes the kinetic prefactor in the nucleation rate expression. The terms $k_{\mathrm{B}} T / h$ and $\Delta F_{\text {act }} /\left(k_{\mathrm{B}} T\right)$ are the frequency and free energy barrier (in thermal units) of a solute molecule to jump from the solution to the crystalline nucleus respectively, where $h$ denotes the Planck constant. The quantity $\tau_{\text {ind }}$ is the induction time, defined as the time the system spent at constant droplet composition prior to homogeneous nucleation of the first supercritical nucleus.

To find the root of Eq. (6), i.e. the droplet radius at the onset of efflorescence, one has to consider a closure condition to determine the relative solute concentration as a function of the initial and residual core radii and the droplet radius. The closure condition is given by the condition of preserving the salt mass in the droplet, written in the form of a composition-geometry implicit relation $\mathcal{F}_{\text {comp-geom }}\left(x, R_{\mathrm{N}}, R_{\mathrm{N}}^{\prime}, R\right)=0$. With consideration of this relation, one can determine $x_{\text {effl }}$ and $R_{\text {effl }}=R(\mathrm{ERH})$ from the transcendental Eq. (6). For known $R_{\text {effl }}$, the efflorescence humidity, $\mathrm{ERH}=100 \% \times S_{\mathrm{eff}}^{(\beta)}$, is the root of the relation $R=f\left(T, R_{\mathrm{N}}, S^{(\beta)}\right)$, referring to the solution droplet with a completely dissolved residual core $\left(R_{\mathrm{N}}^{\prime}=0\right)$ (see Sect. S2.2 in the Supplement).

\subsection{Thermophysical parameters for the aqueous sodium chloride system}

For application of the calculus to an aqueous sodium chloride system, various thermodynamic and interfacial quantities must be known as input parameters, which were taken from the literature and/or derived employing additional assumptions:

- The solvent and solute activities $a_{\text {solvent }}(x)$ and $a_{\text {solute }}(x)$ for nonideal $\mathrm{NaCl}$ solution are determined from the Ally-Braunstein statistical mechanics theory of multilayer adsorption of water on inorganic salts (Ally and Braunstein, 1998) according to Sect. S3.1 in the Supplement.

- The partial molecular volumes $v^{(\beta \rightarrow \alpha)}(x), v^{(\gamma \rightarrow \alpha)}(x)$, and $v^{(\gamma)}$ are determined according to Sect. S3.2 in the Supplement. 
- The composition-geometry relation $\mathcal{F}_{\text {comp-geom }}\left(x, R_{\mathrm{N}}, R_{\mathrm{N}}^{\prime}, R\right)=0$ has been derived in Sect. S3.3 and is given by Eq. (S120) in the Supplement.

- The relative solute concentration of sodium chloride solubility in water, $x_{\infty}$, is given in Sect. S3.4 in the Supplement.

- The activation energy for solution/solute interfacecrossing diffusion, $\Delta F_{\text {act }}(T, x)$, has been determined according to Sect. S3.5 in the Supplement.

- For the induction time, a value of $\tau_{\text {ind }}=1 \mathrm{~s}$ has been used (Gao et al., 2007).

- For the surface tension of an aqueous $\mathrm{NaCl}$ solution a fixed value of $\sigma_{\infty}^{(\alpha \beta)}=0.083 \mathrm{~J} \mathrm{~m}^{-2}$ according to Russell and Ming (2002) was used (see Sect. S3.6 in the Supplement).

- Based on computer simulations of Li (2009), the reference value of the vapour/solid interfacial energy was specified as $\sigma_{\infty}^{(\beta \gamma)}=0.24 \mathrm{~J} \mathrm{~m}^{-2}$ but varied within the framework of sensitivity studies (see Sect. S3.6 in the Supplement).

- Owing to their large uncertainties, both the solution/solute interfacial energy, $\sigma_{\infty}^{(\alpha \gamma)}$, and the film correlation length, $l^{(\star)}$, have been estimated from measured ERH and DRH values (see Sects. S3.6 and S3.7 in the Supplement).

\section{Estimation of the solution/solute interfacial energy and the film correlation length}

\subsection{Determination of the solution/solute interfacial energy}

The "best guess" estimation of $\sigma_{\infty}^{(\alpha \gamma)}$ proceeds in three steps.

Firstly, from combination of the generalised GKK equation, $\mathcal{F}_{\mathrm{GKK}}$, and the composition-geometry relation, $\mathcal{F}_{\text {comp-geom, }}$, specified to the case of a completely dissolved residual core $\left(R_{\mathrm{N}}^{\prime}=0\right)$, one gets the efflorescence radius, $R_{\text {effl }}$, as a function of the measured vapour saturation ratio at efflorescence, $S_{\text {effl, meas }}^{(\beta)}\left(R_{\mathrm{N}}\right)$.

Secondly, from $\mathcal{F}_{\text {comp-geom }}$ one gets the relative solute concentration at efflorescence, $x_{\text {effl }}$, as a function of $R_{\text {effl }}$.

Thirdly, the solution/solute interface energy is adjusted in such a way that at the measured ERH exactly one crystallite forms inside the volume of the homogeneous droplet, $V_{R}$, effl, during the induction time.

The expression for the homogeneous nucleation rate, $J_{\text {hom }}$, is given in Sect. S2.2, Eq. (S81) in the Supplement. On this base, one can define a suitable physical constraint in form of an implicit function $\mathcal{F}^{(\sigma)}\left(\sigma_{\infty}^{(\alpha \gamma)}\right)=0$, the numerical root of which is the sought-after interfacial energy $\sigma_{\infty}^{(\alpha \gamma)}$.

The whole calculus reads

$$
\begin{aligned}
& \mathcal{F}_{\text {GKK }}+\mathcal{F}_{\text {comp-geom }} \leadsto R_{\text {effl }}=f\left(T, R_{\mathrm{N}}, S_{\text {effl, meas }}^{(\beta)}\right) \\
& \mathcal{F}_{\text {comp-geom }} \leadsto x_{\text {effl }}=x_{\text {effl }}\left(R_{\text {effl }}\right) \\
& \mathcal{F}^{(\sigma)}\left\{\sigma_{\infty}^{(\alpha \gamma)}\right\}=\ln \underbrace{\left[J_{\text {hom }}\left\{\sigma_{\infty}^{(\alpha \gamma)}, x_{\text {effl }}, \ldots\right\} V_{R, \text { effl }} \tau_{\text {ind }}\right]}_{!}=0 .
\end{aligned}
$$

The sought-after value of $\sigma_{\infty}^{(\alpha \gamma)}$ is found when, for given $S_{\text {effl, meas }}\left(R_{\mathrm{N}}\right)$, the constraint $\mathcal{F}^{(\sigma)}\left\{\sigma_{\infty}^{(\alpha \gamma)}\right\} \stackrel{!}{=} 0$ is fulfilled.

\subsection{Determination of the correlation length}

Similarly, the "best guess" estimation of $l^{(\star)}$ proceeds in the following three steps.

Firstly, $\sigma_{\infty}^{(\alpha \gamma)}$ obtained from the previous step is used to determine the spreading coefficient $s$.

Secondly, the theoretical deliquescence humidity, $\mathrm{DRH}_{\mathrm{SSR}}$, is determined using the SSR theory according to Sect. 2.1.3.

Thirdly, $l^{(\star)}$ is adjusted in such a way that the theoretical value $\mathrm{DRH}_{\mathrm{SSR}}$ equals the measured value $\mathrm{DRH}_{\text {meas }}\left(R_{\mathrm{N}}\right)$ for given radius of the dry particle.

On this base, one can define another physical constraint in form of an implicit function $\mathcal{F}^{(l)}\left(l^{(\star)}\right)=0$, the numerical root of which is the sought-after length scale $l^{(\star)}$ :

$$
\mathcal{F}^{(l)}\left\{l^{(\star)}\right\}=\operatorname{DRH}_{\text {SSR }}\left\{l^{(\star)}, \ldots\right\}-\mathrm{DRH}_{\text {meas }}=0 .
$$

The sought-after value of $l^{(\star)}$ is found when, for given $\operatorname{DRH}_{\text {meas }}\left(R_{\mathrm{N}}\right)$, the constraint $\mathcal{F}^{(l)}\left\{l^{(\star)}\right\} \stackrel{!}{=} 0$ is fulfilled.

The functions $\mathcal{F}^{(\sigma)}\left(\sigma_{\infty}^{(\alpha \gamma)}\right)=0$ and $\mathcal{F}^{(l)}\left(l^{(\star)}\right)=0$ serve as additional side conditions to close the model.

\subsection{Size dependence of deliquescence and efflorescence humidities}

Based on laboratory studies, Biskos et al. (2006a) derived the following power law fits for the size dependence of the deliquescence and efflorescence relative humidity values, DRH and $\mathrm{ERH}$, of $\mathrm{NaCl}$ particles with dry mobility equivalent diameters in the range $6<D_{\mathrm{m} \text {, dry }} / \mathrm{nm}<60$ (see Fig. 1):

$$
\begin{aligned}
& \frac{\mathrm{DRH}_{\text {Biskos }}}{\% \mathrm{rh}}=213\left(\frac{D_{\mathrm{m}, \mathrm{dry}}}{\mathrm{nm}}\right)^{-1.6}+76, \\
& \frac{\mathrm{ERH}_{\text {Biskos }}}{\% \mathrm{rh}}=213\left(\frac{D_{\mathrm{m}, \mathrm{dry}}}{\mathrm{nm}}\right)^{-1.65}+44 .
\end{aligned}
$$

For the present purposes, we have replaced the dry mobility equivalent diameter, $D_{\mathrm{m} \text {, dry }}$, by the dry volume equivalent 
Table 1. Determination of the efflorescence radius $R(\mathrm{ERH})$, the efflorescence molality $m(\mathrm{ERH})$, the efflorescence mass fraction $x_{\mathrm{m}}(\mathrm{ERH})$, and the liquid/solid interface energy $\sigma_{\infty}^{(\alpha \gamma)}$ according to Eq. (7) for three different $\triangle \mathrm{ERH}$ values (see Fig. 2).

\begin{tabular}{cccccc}
\hline Graph & $\begin{array}{c}\Delta \text { ERH } \\
\% \mathrm{rh}\end{array}$ & $\begin{array}{c}R(\mathrm{ERH}) \\
\mathrm{nm}\end{array}$ & $\begin{array}{c}m(\mathrm{ERH}) \\
\mathrm{molkg}^{-1}\end{array}$ & $\begin{array}{c}x_{\mathrm{m}}(\mathrm{ERH}) \\
1\end{array}$ & $\begin{array}{c}\sigma_{\infty}^{(\alpha \gamma)} \\
\mathrm{J} \mathrm{m}^{-2}\end{array}$ \\
\hline 1 & -1.0 & 7.28 & 15.95 & 0.4825 & 0.0894 \\
2 & 0.0 & 7.32 & 15.58 & 0.4765 & 0.088 \\
3 & +1.0 & 7.36 & 15.20 & 0.4705 & 0.0866 \\
\hline
\end{tabular}

diameter, $D_{\mathrm{V}, \text { dry }}{ }^{7}$. For the relative humidity measurements at several points throughout the apparatus using capacitance sensors, Biskos et al. (2006b, see p. 98 therein) communicated an "accuracy" of $\pm 2.5 \%$ rh. In their abstract, however, the authors stated that the power law fits were calibrated with "less than $1 \%$ rh uncertainty." Within the framework of sensitivity studies we have varied the efflorescence and deliquescence humidities as follows:

$\mathrm{ERH}=\mathrm{ERH}_{0}+\Delta \mathrm{ERH}$,
$\mathrm{DRH}=\mathrm{DRH}_{0}+\Delta \mathrm{DRH}$.

Here, $\mathrm{ERH}_{0}$ and $\mathrm{DRH}_{0}$ are the nominal values of the efflorescence and deliquescence humidity according to Eq. (9), and $\triangle E R H$ and $\triangle \mathrm{DRH}$ are the corresponding uncertainties, which are assumed to be independent from each other. Within the framework of sensitivity studies we have assumed three different values for the uncertainties: $-1 \% \mathrm{rh}, 0 \% \mathrm{rh}$, $+1 \%$ rh.

\section{Results and discussion}

\subsection{Reference case calculation}

The subsequent calculations were performed at $T=298 \mathrm{~K}$ for a dry $\mathrm{NaCl}$ particle radius of $R_{\mathrm{N}}=5 \mathrm{~nm}$, corresponding to $\mathrm{DRH} \approx 81 \%$ rh and ERH $\approx 47 \%$ rh according to Eq. (9).

\footnotetext{
${ }^{7}$ The relation between the dry mobility equivalent diameter and the dry volume equivalent diameter, $D_{\mathrm{V}}$, dry, reads (e.g. Romakkaniemi et al., 2001, Hämeri et al., 2001)

$D_{\mathrm{V}, \text { dry }}=\left[\frac{1}{\chi} \frac{C\left(D_{\mathrm{V}, \mathrm{dry}}\right)}{C\left(D_{\mathrm{m}, \mathrm{dry}}\right)}\right] D_{\mathrm{m}, \mathrm{dry}}, \quad \chi=1.08$,

$C(D)=1+\left(\frac{133}{D / \mathrm{nm}}\right) \times\left[1.142+0.588 \exp \left(-\frac{0.999 D / \mathrm{nm}}{133}\right)\right]$.

Here, $\chi$ denotes the shape factor and $C(D)$ the Cunningham slip correction factor. For $D_{\mathrm{m}, \text { dry }} \approx D_{\mathrm{V} \text {, dry }}=30 \mathrm{~nm}$ we obtain $\mathrm{DRH}_{\text {Biskos }}=76.92 \%$ and $\mathrm{ERH}_{\text {Biskos }}=44.78 \%$. With consideration of the Cunningham slip correction we obtain $D_{\mathrm{m} \text {, dry }}=$ $31.2 \mathrm{~nm}, \mathrm{DRH}_{\text {Biskos }}=76.87 \%$, and $\mathrm{ERH}_{\text {Biskos }}=44.73 \%$. The difference compared to the approximative results is rather small and can be neglected for the present purposes.
}

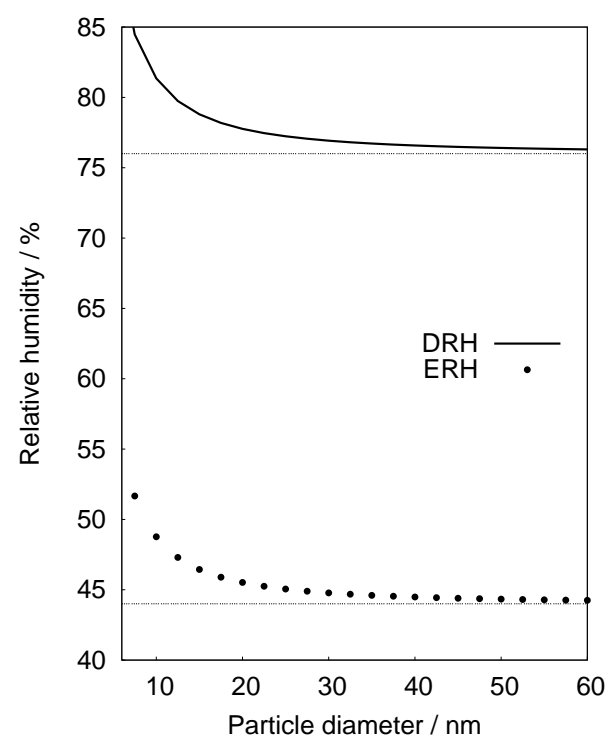

Figure 1. Empirically derived power law fits of the size dependence of the deliquescence and efflorescence relative humidity values, $\mathrm{DRH}$ and $\mathrm{ERH}$, of $\mathrm{NaCl}$ particles with dry mobility equivalent diameters in the range $6<D_{\mathrm{m} \text {, dry }} / \mathrm{nm}<60$ according to Eq. (9) experimentally determined by Biskos et al. (2006b).

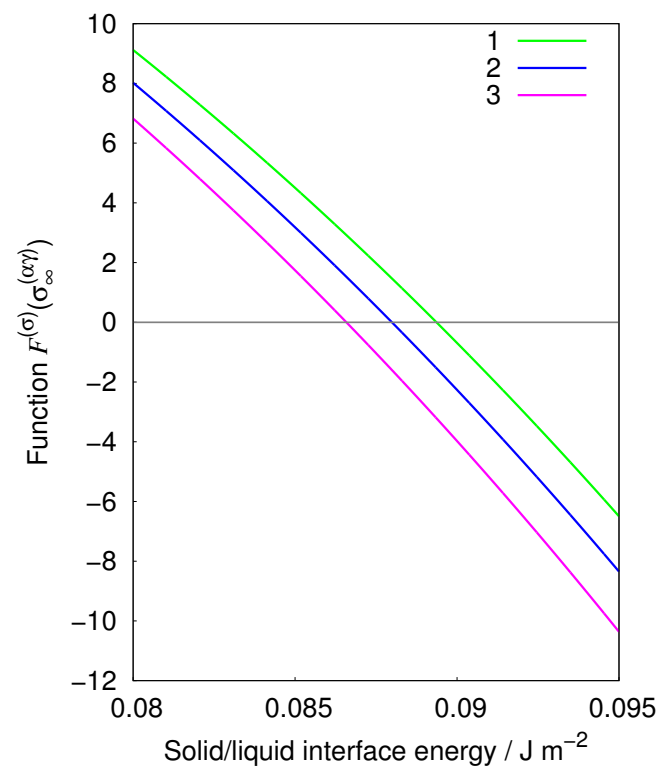

Figure 2. Function $\mathcal{F}^{(\sigma)}$ in dependence of the solution/solute interfacial energy $\sigma_{\infty}^{(\alpha \gamma)}$ according to Eq. (7) for three different ERH values $\mathrm{ERH}=\mathrm{ERH}_{0}+\Delta \mathrm{ERH}$ with $\mathrm{ERH}_{0}$ denoting the nominal value of ERH according to the power law fit given by Eq. (9) with $\triangle \mathrm{ERH}$ optionally assuming $-1 \% \mathrm{rh}, 0 \% \mathrm{rh}$, and $+1 \% \mathrm{rh}$, corresponding to graphs 1,2 , and 3 respectively. The sought-after value $\sigma_{\infty}^{(\alpha \gamma)}$ is the abscissa value corresponding to the functional value $\mathcal{F}^{(\sigma)}\left(\sigma_{\infty}^{(\alpha \gamma)}\right)=0$, indicated by the solid horizontal line.

At first, we start with the determination of $\sigma_{\infty}^{(\alpha \gamma)}$ with consideration of the uncertainty in the ERH measurement (see 
Table 2. Determination of the correlation length $l^{(\star)}$ according to Eq. (7) for six possible combinations of $\triangle E R H$ and $\triangle D R H$ values (see Fig. 3). The spreading coefficient $s$ is added.

\begin{tabular}{crrcc}
\hline Graph & $\begin{array}{c}\Delta \text { ERH } \\
\% \text { rh }\end{array}$ & $\begin{array}{c}\Delta \text { DRH } \\
\% \mathrm{rh}\end{array}$ & $\begin{array}{c}l^{(\star)} \\
\mathrm{nm}\end{array}$ & $\begin{array}{c}s \\
\mathrm{~J} \mathrm{~m}^{-2}\end{array}$ \\
\hline 11 & -1.0 & -1.0 & 1.52 & 0.0676 \\
21 & 0.0 & -1.0 & 1.51 & 0.069 \\
31 & +1.0 & -1.0 & 1.5 & 0.07 \\
12 & -1.0 & 0.0 & 0.98 & 0.0676 \\
22 & 0.0 & 0.0 & 0.98 & 0.069 \\
32 & +1.0 & 0.0 & 1.05 & 0.07 \\
13 & -1.0 & +1.0 & 0.7 & 0.0676 \\
23 & 0.0 & +1.0 & 0.7 & 0.069 \\
33 & +1.0 & +1.0 & 0.7 & 0.07 \\
\hline
\end{tabular}

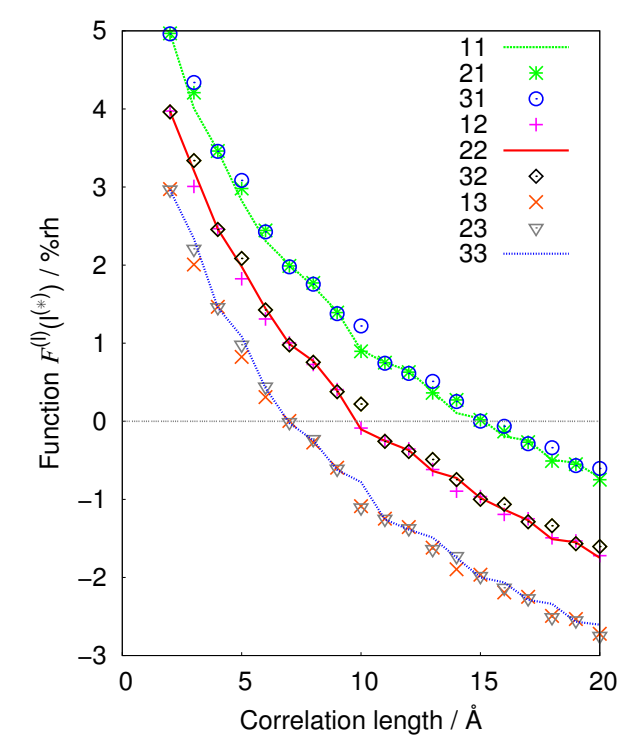

Figure 3. Function $\mathcal{F}^{(l)}$ dependent on the correlation length $l^{(\star)}$ according to Eq. (8) for six possible combinations of $\triangle \mathrm{ERH}$ and $\triangle \mathrm{DRH}$ values according to Table 2 . The sought-after value $l^{(\star)}$ is the abscissa value corresponding to the ordinate value $\mathcal{F}^{(l)}\left(\sigma_{\infty}^{(\alpha \gamma)}\right)=0$, indicated by the solid horizontal line.

Table 1 and Fig. 2). Figure 2 shows the function $\mathcal{F}^{(\sigma)}$ in dependence of the solution/solute interfacial energy $\sigma_{\infty}^{(\alpha \gamma)}$ according to Eq. (7) for three different $\triangle E R H$ values corresponding to graphs 1,2 , and 3 in Fig. 2. For the best guess of the solution/solute interfacial energy at the nominal ERH a value of $\sigma_{\infty}^{(\alpha \gamma)} \approx 0.088 \mathrm{~J} \mathrm{~m}^{-2}$ was obtained, which is considerably larger than the value of $\sigma_{\infty}^{(\alpha \gamma)}=0.029 \pm$ $0.020 \mathrm{~J} \mathrm{~m}^{-2}$ given by Russell and Ming (2002, see references therein) but is close to the value of $\sigma_{\infty}^{(\alpha \gamma)} \approx 0.0895 \mathrm{~J} \mathrm{~m}^{-2} \mathrm{ob}-$ tained by Gao et al. (2007).

Secondly, we determined $l^{(\star)}$ with consideration of the uncertainty in both the ERH and DRH measurements (see Table 2 and Fig. 3). Figure 3 shows the function $\mathcal{F}^{(l)}$ in de-

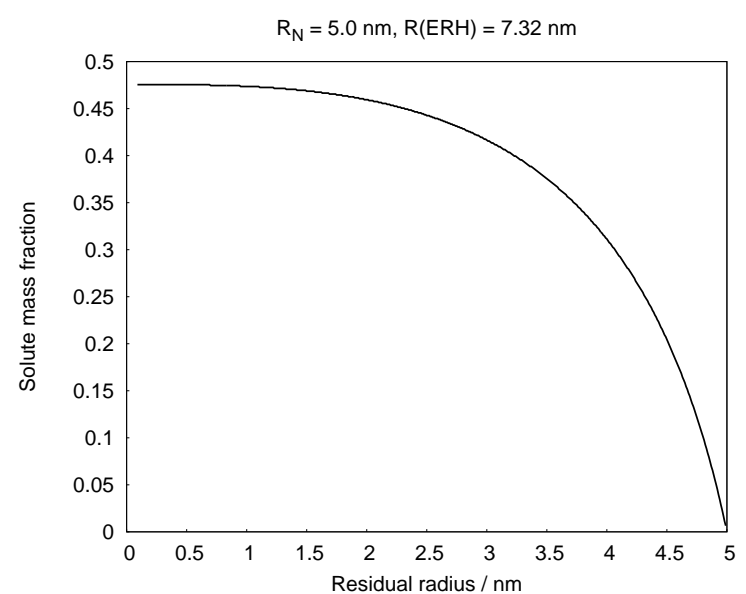

Figure 4. Solute mass fraction $x_{\mathrm{m}}$ as a function of the residual radius $R_{\mathrm{N}}^{\prime}$.

pendence of the correlation length $l^{(\star)}$ according to Eq. (8) for different ERH and DRH values. The sensitivity of the correlation length to uncertainties in the ERH measurements is very small. However, for the assumed DRH uncertainty, the correlation length varies in the range $l^{(\star)} \approx(0.7-1.5) \mathrm{nm}$ with a best guess value of $l^{(\star)} \approx 1 \mathrm{~nm}$ at the nominal DRH value. This value is somewhat larger than the value proposed by Marčelja and Radić (1976) $\left(l^{(\star)} \approx 0.3 \mathrm{~nm}\right)$ and the values obtained from density functional theory and discussed in detail in Sect. S3.7 in the Supplement $\left(l^{(\star)} \approx(0.4-0.54) \mathrm{nm}\right)$. However, considering that (i) the present approach is based on completely different assumptions than DFT and (ii) the present approach employs a comprehensive set of experimental thermophysical data of the sodium chloride/water system, it is justified to assess the achieved agreement as very $\operatorname{good}^{8}$. The application of the employed here theory to experimental data allows the determination of interface parameters which are reconcilable with predictions from molecular theories. The subsequent calculations have been performed using the best guess values of $\sigma_{\infty}^{(\alpha \gamma)}$ and $l^{(\star)}$.

Figure 4 displays the dependence of the solute mass fraction as a function of the residual core radius at the efflorescence radius. A vanishing residual core, $R_{\mathrm{N}}^{\prime} \rightarrow 0$, corresponds to a homogenous solution droplet in which the solute mass fraction attains its maximum. According to Fig. 4, the solute mass fraction at efflorescence amounts to $x_{\mathrm{m}} \approx 0.48$. The efflorescence radius, i.e. the radius of a homogeneous solution droplet at the onset of crystallisation, was found to be $R(\mathrm{ERH}) \approx 7.3 \mathrm{~nm}$, corresponding to a molality of $m(\mathrm{ERH}) \approx 15.6 \mathrm{~mol} \mathrm{~kg}^{-1}$ and a solution saturation ratio of $S^{(\alpha)} \approx 2.53$ required for homogeneous crystallisation to occur.

\footnotetext{
${ }^{8}$ It should be mentioned, of course, that the realisation of an adopted RH uncertainty of only $1 \%$ rh is a very great experimental challenge.
} 


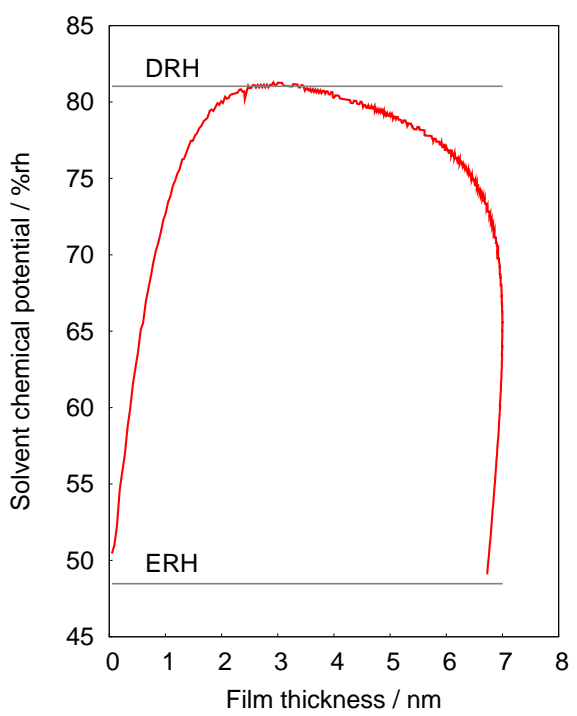

Figure 5. Chemical potential of solvent molecules in the liquid film given in thermal units, $b^{(\beta \rightarrow \alpha)}$, as a function of the film thickness, $h$, according to Eq. (5) at $R_{\mathrm{N}}=5 \mathrm{~nm}$.

Figure 5 displays the chemical potential of solvent molecules in the liquid film given in thermal units, $b^{(\beta \rightarrow \alpha)}$, as a function of the film thickness, $h$, according to Eq. (5). The difference between the actual dimensionless chemical potential of the vapour, $b^{(\beta)}=\ln S^{(\beta)}$, and $b^{(\beta \rightarrow \alpha)}$ can be interpreted as a driving force of vapour condensation. It appears that in the initial stages of water uptake, when the film is still very thin, the values of $b^{(\beta \rightarrow \alpha)}$ are very low, i.e. the condensation driving force is very large. This effect originates from the contribution of the disjoining pressure. Without the consideration of the disjoining pressure, the water uptake by hygroscopic particles at RH well below DRH cannot be explained (see Kuni et al., 1996). Condensation occurs as long as the actual value of $b^{(\beta)}$ is larger than $b^{(\beta \rightarrow \alpha)}$. The maximum value of $b^{(\beta \rightarrow \alpha)}$ defines the DRH value. In the present case, deliquescence sets in at a film thickness of $h(\mathrm{DRH}) \approx 2.5 \mathrm{~nm}$ at $R_{\mathrm{N}}=5 \mathrm{~nm}$.

The numerical solution of the OF Eq. (3) delivers the drop radius $R$ as a function of the residual radius $R_{\mathrm{N}}^{\prime}$, which is depicted in Fig. 6 for $R_{\mathrm{N}}=5 \mathrm{~nm}$. The maximum of the function $R\left(R_{\mathrm{N}}^{\prime}\right)$ represents the stability limit of the heterogeneous droplet; i.e. above this value a heterogeneous solution droplet cannot exist in thermodynamic equilibrium with a residual core. Below the maximum droplet radius and above the efflorescence radius, $R(\mathrm{ERH})$, there exist two numerical solutions of the $\mathrm{OF}$ equation; i.e. the equilibrium droplet radius $R$ is reconcilable with two different sizes of the residual core radius $R_{\mathrm{N}}^{\prime}$. The lower of the two horizontal solid lines depicted in Fig. 6 indicates the efflorescence radius, $R(\mathrm{ERH})$, as determined from previous steps ${ }^{9}$.

\footnotetext{
${ }^{9}$ The solution of the OF equation (thick solid line in Fig. 6) is intrinsically not restricted to droplet sizes above the efflorescence
}

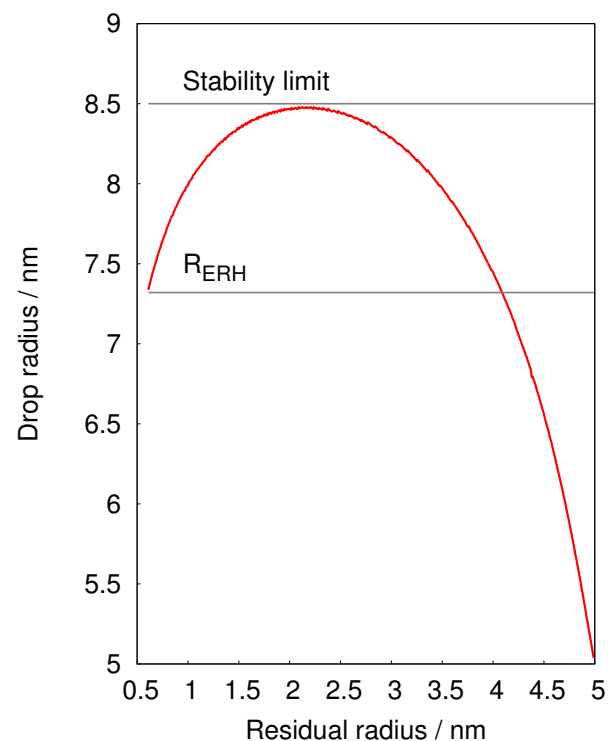

Figure 6. Drop radius $R$ as a function of residual radius $R_{\mathrm{N}}^{\prime}$ as the numerical solution of the Ostwald-Freundlich equation (3) at $R_{\mathrm{N}}=$ $5 \mathrm{~nm}$.

Figure 7 shows the humidity growth factor GF as a function of RH according to Eq. (4) for $R_{\mathrm{N}}=5 \mathrm{~nm}$. The solid line refers to the homogeneous solution droplet with completely dissolved residual core, $R_{\mathrm{N}}^{\prime}=0$, and the dotted curves refer to the heterogeneous solution droplet with partially dissolved residual core, $R_{\mathrm{N}}^{\prime} \neq 0$. Let us consider a dry particle which is placed in an atmosphere free of vapour at the beginning. Upon humidification by increasing $\mathrm{RH}$, the dry particle initially remains seemingly "inert" against hydration until about $40 \%$ rh. However, the adsorbed film exist even in this stage as a very thin film in equilibrium with vapour. Close to this humidity value the dry particle starts to take up remarkable amounts of water molecules, as seen from the rapid increase of the growth factor; at this stage the film is still thermodynamically stable but already thicker. At the DRH, a liquid film forms without an activation barrier, the residual core fast vanishes, and upon further increase of the $\mathrm{RH}$, the growth factor evolves according to the solid line referring to the homogeneous droplet ${ }^{10}$.

Upon dehumidification of the ambient atmosphere the droplet shrinks. As the mass of the completely dissolved residual core remains conserved inside the droplet, the so-

radius. In the present approach, however, the efflorescence radius has been considered as an additional physical constraint imposing a lower limit on the physically accessible drop radius.

${ }^{10} \mathrm{We}$ emphasise that at all relative humidities below the DRH, a thermodynamically stable film forms without an activation barrier. In these cases the stable equilibrium of the film corresponds to a deep minimum of the work of formation. In the vicinity of the $\mathrm{DRH}$, the barrier for transition to a droplet with completely dissolved nucleus vanishes. Hence, one can say that at the DRH a homogeneous droplet forms without an activation barrier. 


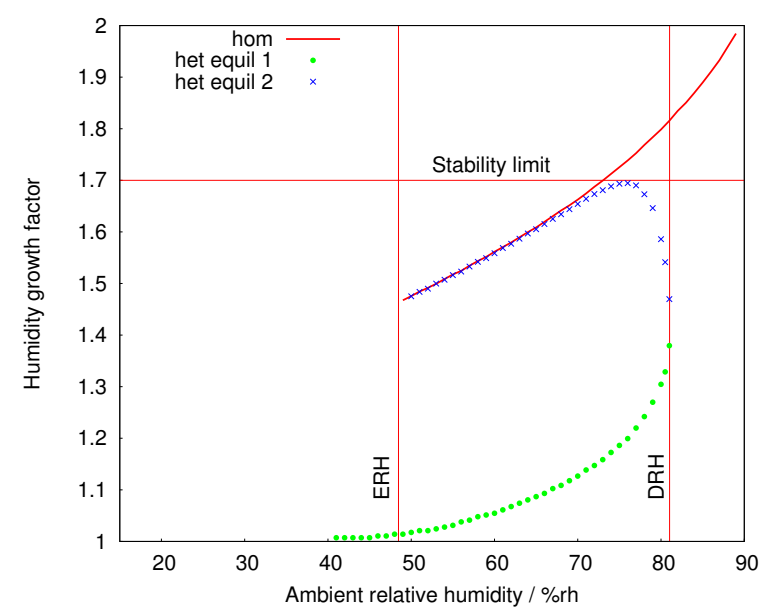

Figure 7. Humidity growth factor GF as function of RH according to Eq. (4) for $R_{\mathrm{N}}=5 \mathrm{~nm}$. The solid line represents the numerical solution of the GKK equation for the homogeneous solution droplet with completely dissolved residual core, $R_{\mathrm{N}}^{\prime}=0$. The dotted curves (symbols " $x$ " and " $\bullet$ ') represent the two numerical roots of the combined Ostwald-Freundlich and Gibbs-Kelvin-Köhler equations for the heterogeneous droplet with partially dissolved residual core, $R_{\mathrm{N}}^{\prime} \neq 0$. The graph "het equil 1" corresponds to the thermodynamically stable heterogeneous equilibrium droplet and the graph "het equil 2" to the conditionally stable heterogeneous equilibrium droplet. See also Fig. 8.

lute mass fraction in the droplet will increase until a solution supersaturation is achieved at which homogeneous crystallisation sets in. As described previously, the determination of the conditions of efflorescence relies on the employment of CNT and the use of several thermophysical parameters, among which the kinetic prefactor in the nucleation rate expression is subject to some uncertainties owing to limited availability of data on the energy barrier for interfacecrossing diffusion. In the range $\mathrm{ERH} \leq \mathrm{RH} \leq \mathrm{DRH}$ there exist two thermodynamically stable numerical solutions of the calculus: one refers to a heterogeneous, the other to a homogeneous, droplet. For the heterogeneous droplet there exist two branches corresponding to two different GF values (label "het equil 1" with symbol "•", label "het equil 2" with symbol " $\times$ "), but as shown by Shchekin and Shabaev (2010) they cannot coexist. The heterogeneous nucleation pathway "het equil 1" corresponds to a thermodynamically stable heterogeneous equilibrium droplet and the pathway "het equil 2" to a thermodynamically conditionally stable heterogeneous equilibrium droplet. The efflorescence transition from a homogeneous to a heterogeneous droplet corresponds to a jump from the solid line to the pathway "het equil 2". Figure 7 shows that the specification of the temperature and humidity is in fact a necessary but not sufficient condition for the full characterisation of the thermodynamic state of the system; the full characterisation requires also the specification of the "history" of the thermohumid conditions.

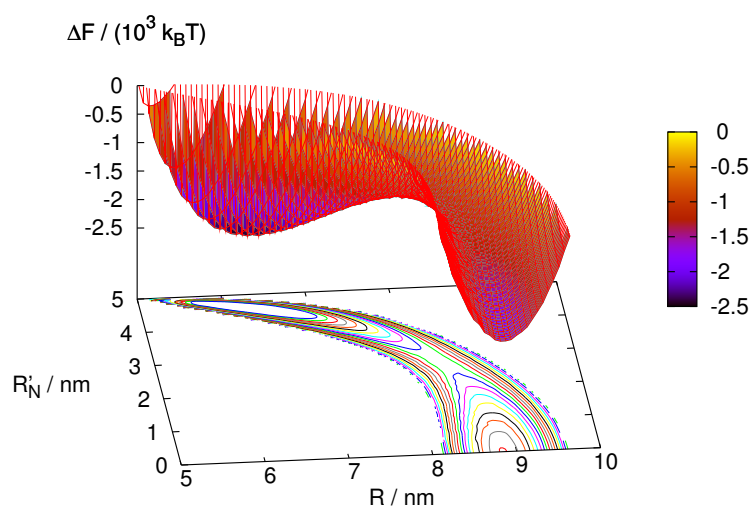

Figure 8. Dimensionless 2-D work of droplet formation, $\Delta F /\left(k_{\mathrm{B}} T\right)$, as a function of drop radius $R$ and the residual core radius $R_{\mathrm{N}}^{\prime}$ according to Eq. (1) for at $\mathrm{RH}=78 \%$ rh. One can see two minima in the formation work, which are separated by a saddle point. These three characteristic points represent the three equitable thermodynamic states the aerosol systems can adopt at $(T, \mathrm{RH})=(298 \mathrm{~K}, 78 \% \mathrm{rh})$. The first minimum at about $\left(R_{\mathrm{N}}^{\prime}, R\right) \approx$ $(4.5 \mathrm{~nm}, 6.5 \mathrm{~nm})$ corresponds to the existence of a thermodynamically stable heterogeneous droplet, the second minimum at about $\left(R_{\mathrm{N}}^{\prime}, R\right) \approx(0 \mathrm{~nm}, 8.8 \mathrm{~nm})$ to a thermodynamically stable homogeneous solution droplet, and the saddle point at about $\left(R_{\mathrm{N}}^{\prime}, R\right) \approx$ $(3 \mathrm{~nm}, 8.8 \mathrm{~nm})$ to the existence of conditionally stable heterogeneous droplet.

Figure 8 shows the dimensionless 2-D work of droplet formation, $\Delta F /\left(k_{\mathrm{B}} T\right)$, as a function of drop radius $R$ and the residual core radius $R_{\mathrm{N}}^{\prime}$ according to Eq. (1) at $\mathrm{RH}=78 \% \mathrm{rh}$ i.e. just below the deliquescence stage. One can clearly see the existence of two minima in the formation work, which are separated by a saddle point. These three points represent the three possible (and equitable) thermodynamic states the aerosol system can adopt at $(T, \mathrm{RH})=(298 \mathrm{~K}, 78 \% \mathrm{rh})$. The first minimum at about $\left(R_{\mathrm{N}}^{\prime}, R\right) \approx(4.5 \mathrm{~nm}, 6.5 \mathrm{~nm})$ corresponds to the existence of a thermodynamically stable heterogeneous droplet, the second minimum at about $\left(R_{\mathrm{N}}^{\prime}, R\right) \approx$ $(0 \mathrm{~nm}, 8.8 \mathrm{~nm})$ to a thermodynamically stable homogeneous solution droplet, and the saddle point at about $\left(R_{\mathrm{N}}^{\prime}, R\right) \approx$ $(3 \mathrm{~nm}, 8.8 \mathrm{~nm})$ to the existence of conditionally stable heterogeneous droplet. The latter is thermodynamically stable against small fluctuations of $R_{\mathrm{N}}^{\prime}$ and $R$ along a trajectory across the "valley" but thermodynamically unstable against small fluctuations of $R_{\mathrm{N}}^{\prime}$ and $R$ along a trajectory across the "ridge". For detailed analysis of this conditional stability the reader is referred to Shchekin et al. (2013).

\subsection{Sensitivity studies}

\subsubsection{Influence of the solution surface tension}

Figure 9, in comparison with Fig. 7, shows the influence of the solution surface tension on the hygroscopic growth factor. 
The derivation of the calculus relies on the assumption that the vapour/solution surface tension and the solution/solute interfacial energy are independent of the solution concentration. In order to study the sensitivity of the model results against the special choice of the surface tension of the droplet, we have performed a comparative run with $\sigma_{\infty}^{(\alpha \beta)}=\sigma_{\mathrm{W}}=0.072 \mathrm{~J} \mathrm{~m}^{2}$, where $\sigma_{\mathrm{W}}$ is the surface tension of pure water (calculations have been performed for the nominal values of experimental ERH and DRH). For a solution droplet in which a $\mathrm{NaCl}$ core with radius $R_{\mathrm{N}}=5 \mathrm{~nm}$ has been completely dissolved, the efflorescence radius was found to be $R(\mathrm{ERH}) \approx 7.4 \mathrm{~nm}$ (slightly higher than its reference case (r.c.) value), corresponding to a molality of $m(\mathrm{ERH}) \approx 15.2 \mathrm{~mol} \mathrm{~kg}^{-1}$ (slightly lower than its r.c. value) and a solution saturation ratio of $S^{(\alpha)} \approx 2.47$ (slightly lower than the r.c. value) required for homogeneous crystallisation to occur. At efflorescence, the solute mass fraction amounts $x_{\mathrm{m}} \approx 0.47$ (slightly lower than its r.c. value). For the best guess of the solution/solute interface energy, a value of $\sigma_{\infty}^{(\alpha \gamma)}=0.0866 \mathrm{~J} \mathrm{~m}^{-2}$ has been found (slightly lower than its r.c. value), which results in a spreading coefficient of $s=0.081 \mathrm{~J} \mathrm{~m}^{-2}$ (higher than its r.c. value). For the correlation length the best guess value is $l^{(\star)} \approx 5.4 \AA$ (lower than its r.c. value). The higher spreading coefficient and lower correlation length scale results in a higher value of the disjoining scaling pressure and should promote the disjoining pressure effect in the initial stages of wetting, i.e. when the first condensed monolayers will form on the hygroscopic particle. The influence of $\sigma_{\infty}^{(\alpha \beta)}$ on the humidity growth factor can be seen from comparison of Figs. 7 and 9. The change of the droplet surface tension has seemingly a dramatic impact on the affinity of the hygroscopic particle to take up water. The dry particle starts to take up water already at about $20 \%$ rh, which is much "earlier" than in the reference case. However, the influence of the solution surface tension on the growth factor of the homogeneous droplet is insignificant; hence the recognised sensitivity of the growth factor of the heterogeneous droplet is intrinsically an effect of the disjoining pressure.

\subsubsection{Influence of the vapour/solid interface energy}

Previous studies suggest a large uncertainty in estimates of the solid/vapour interface energy of $\mathrm{NaCl}, \sigma_{\infty}^{(\beta \gamma)} \approx$ $(0.1-0.39) \mathrm{J} \mathrm{m}^{-2}$ (see Sect. S3.6 in the Supplement). Figure 10 shows the calculated correlation length, spreading coefficient, and characteristic disjoining pressure $\left(l^{(\star)}, s\right.$, and $K^{(\star)}=s / l^{(\star)}$ respectively) as a function of $\sigma_{\infty}^{(\beta \gamma)}$, constrained by the condition $s>0$. An increase of the surface energy of a solid enhances the affinity of that solid to take up water by both (i) promoting the spreading of the condensate on the surface and (ii) lowering the correlation length and enhancing the disjoining pressure. This result underpins the need for careful estimations of interface energies of hy-

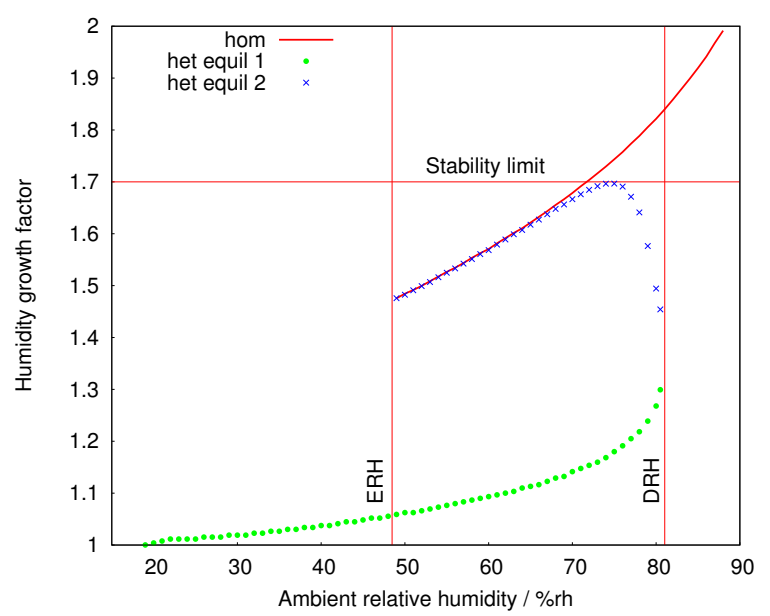

Figure 9. As in Fig. 7 but using the surface tension of pure water, $\sigma_{\infty}^{(\alpha \beta)}=0.072 \mathrm{~J} \mathrm{~m}^{-2}$.

groscopic matter for quantification of the water uptake. The present approach has been applied to the estimation of $\sigma_{\infty}^{(\alpha \gamma)}$ and $l^{(\star)}$ from measured ERH and DRH values. The additional estimation of $\sigma_{\infty}^{(\beta \gamma)}$ would require an further governing condition for a well-measurable observable.

\subsection{3 "Non-ideal" vs. "ideal" solution model}

The original SSR approach was derived adopting the idealsolution approximation of the activities (see footnote ${ }^{6}$ ), i.e. the authors employed a linearisation of the solvent and solute activities that is valid for diluted solutions. In doing so, Shchekin, Shabaev, and Rusanov predicted the first time theoretical curves for the humidity growth factor as a function of the $\mathrm{RH}$. However, for the special $\mathrm{NaCl}$ system considered here and with consideration of the constraints set by the employed thermophysical properties (see Sect. S3 in the Supplement), we could by no means get a numerical solution using the ideal-solution approximation of the activities that is reconcilable with the observed DRH data of Biskos et al. (2006a). For example, replacing in the reference case run the "nonideality" activity model with the ideal-solution approximation we found a solid/liquid interface energy of $\sigma_{\infty}^{(\alpha \gamma)} \approx 0.0593 \mathrm{~J} \mathrm{~m}^{-2}$ for the observed ERH value (see Fig. 11). For the corresponding efflorescence radius we obtained $R(\mathrm{ERH})=5.7 \mathrm{~nm}$, which results in a very high value of the molality at the onset of efflorescence, $m(\mathrm{ERH}) \approx 82 \mathrm{~mol} \mathrm{~kg}^{-1}$. This value corresponds to an extremely high solution supersaturation and is far beyond an experimentally accessible state of the system. In contrast to the possibility of obtaining a value for $\sigma_{\infty}^{(\alpha \gamma)}$ which formally fulfills the adopted constraints, it was impossible to decrease the difference between predicted and observed DRH values to a value smaller than $10 \%$ rh by adjusting the correlation length (see Fig. 12). 

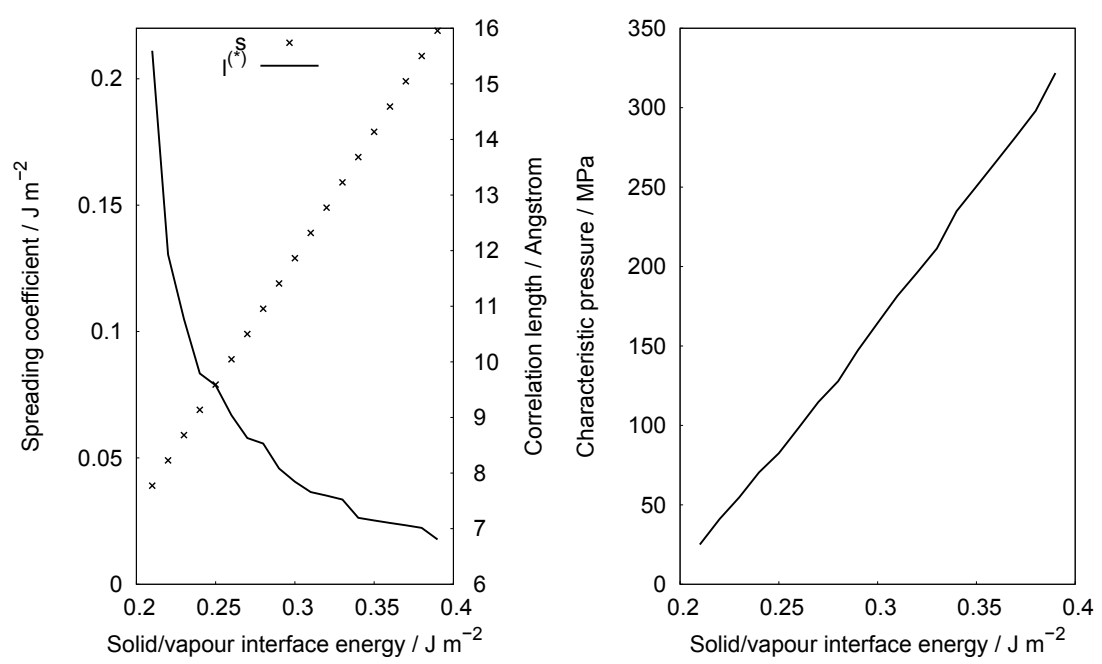

Figure 10. Calculated interfacial parameters as functions of $\sigma_{\infty}^{(\beta \gamma)}$ (with constraint $s>0$ ). Left panel: spreading coefficient $s$ and correlation length $l^{(\star)}$. Right panel: characteristic disjoining pressure $K^{(\star)}=s / l^{(\star)}$.

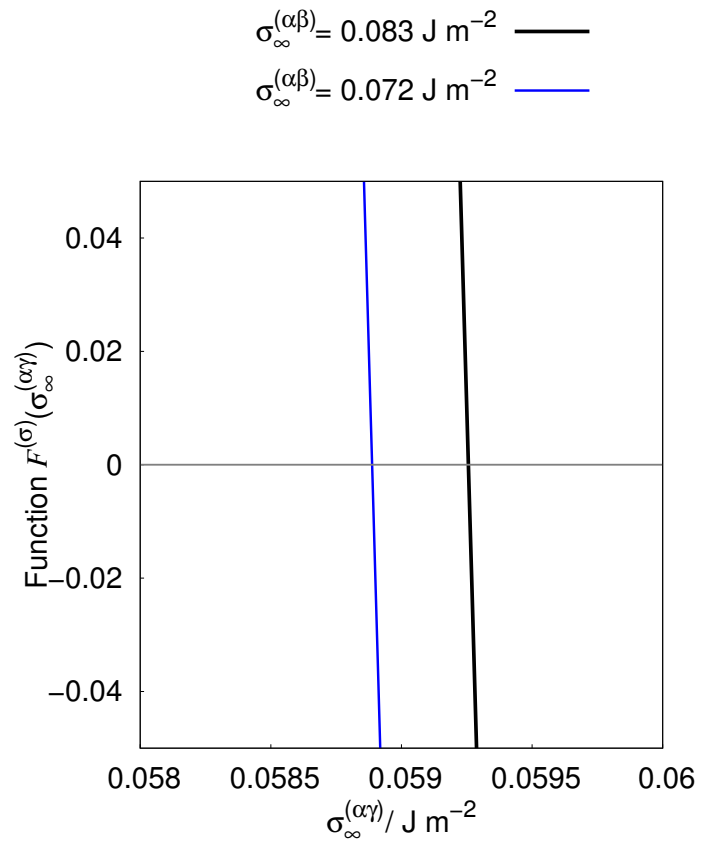

Figure 11. Function $\mathcal{F}^{(\sigma)}$ dependent on the solution/solute interfacial energy $\sigma_{\infty}^{(\alpha \gamma)}$ according to Eq. (7), employing the "ideal solution" limit of the activity model for two different $\sigma_{\infty}^{(\alpha \beta)}$ values. Black graph uses $\sigma_{\infty}^{(\alpha \beta)}=0.083 \mathrm{~J} \mathrm{~m}^{-2}$; blue graph uses $\sigma_{\infty}^{(\alpha \beta)}=$ $0.072 \mathrm{~J} \mathrm{~m}^{-2}$.

However, compared to the ideal-solution limit employed by Shchekin, Shabaev, and Rusanov, the present result is essentially based on consideration of additional physical and physicochemical constraints: (i) employment of the CNT, (ii) using specific hygric, thermodynamic, and interfacial properties obtained from different experimental and mod-

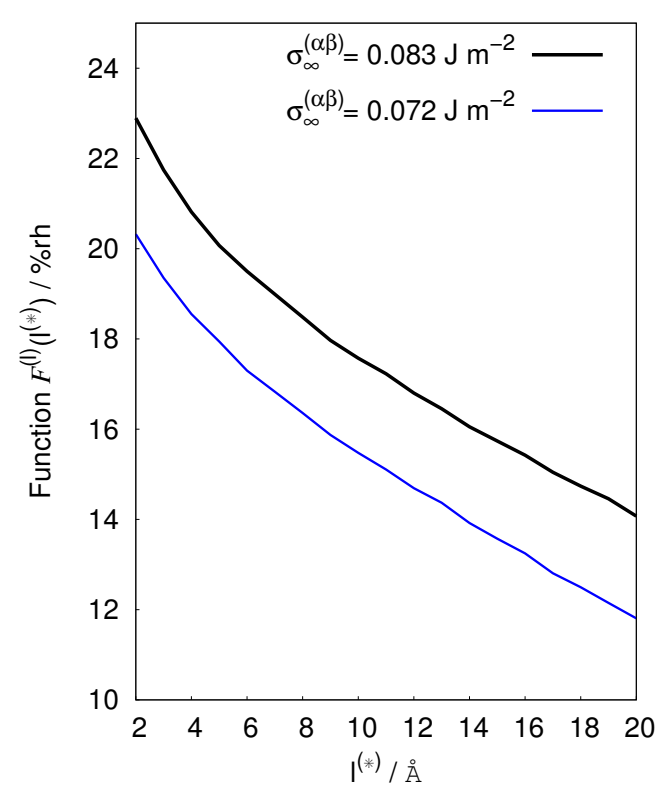

Figure 12. Function $\mathcal{F}^{(l)}$ dependent on the correlation length $l^{(\star)}$ according to Eq. (8), employing the "ideal solution" limit of the activity model for two different $\sigma_{\infty}^{(\alpha \beta)}$ values. Black graph uses $\sigma_{\infty}^{(\alpha \beta)}=0.083 \mathrm{~J} \mathrm{~m}^{-2}$; blue graph uses $\sigma_{\infty}^{(\alpha \beta)}=0.072 \mathrm{~J} \mathrm{~m}^{-2}$.

elling sources. Hence, the nonapplicability of the idealsolution limit does not restrict the physical generality of the SSR approach. A possible candidate for enhancement of the "degrees of freedom" of the present approach is the solubility of the solute in the liquid film. However, as we do not have a profound physical justification for changing the solubility, the "ideal solution" approximation was not further examined here. 


\section{Conclusions}

1. In order to study the growth/shrinking of a hygroscopic nanoparticle during hydration/dehydration in a solvent vapour atmosphere, we have employed a thermodynamic theory proposed by Shchekin, Shabaev, and Rusanov which allows the prediction of the humidity growth factor of both (i) a homogeneous solution droplet with completely dissolved residual core and (ii) a heterogeneous solution droplet with partially dissolved residual core as a function of the ambient relative humidity.

2. For application to a nanometric sodium chloride particle placed in a water vapour atmosphere, we have extended the theory as follows: (i) consideration of the nonideality of the solution through the dependence of the molecular volumes of the solvent and solute molecules in the solution on the solution concentration, (ii) consideration of the nonideality of the solution in the determination of the solute and solvent activities, and (iii) derivation of a CNT-based governing equation for the estimation of the efflorescence properties of a homogeneous solution droplet.

3. It was demonstrated how the solution/solute interface energy and the correlation length of a thin solution film can be determined from a combination of experimentally determinable efflorescence and deliquescence humidities with the present calculus. The solution/solute interface energy was found to be in close agreement with the value proposed by Gao et al. (2007); the correlation length was found to be about $1 \mathrm{~nm}$, which is somewhat higher than previous estimated from the literature. Considering the combination of an extensive calculus, a comprehensive set of thermophysical constraints, and independent ERH/DRH measurements as function of dry particle size, the obtained values of both the solution/solute interface energy and the correlation length scale are surprisingly close to previous estimations. This reflects a satisfying degree of "self-consistency" of the present approach, allowing the retrieval of microscopic interfacial parameters from macroscopic humidity measurements. It also shows the crucial role that humidity metrology plays for the theoretical description of the water uptake by nanometric particles.

4. The question of interest of the present study was the theoretical description of phase transitions of soluble nanoparticles. These particles are suspended in ambient air, which is thermodynamically controlled by macroscopic parameters, namely temperature and relative humidity. The empirical size dependence of deliquescence and efflorescence humidities on nanometric scales underlying the present approach underpins the great im- portance of high-accuracy measurements of nanometric particles under well-controlled thermohumid conditions. Such technically elaborate measurements are a prerequisite for (i) the estimation of interface parameters, (ii) the further enhancement of theoretical concepts to describe such systems, and (iii) the assessment of the predictive power of available models, especially in the heterogeneous nucleation regime.

5. Mirabel et al. (2000) proposed a scenario of prompt deliquescence of particles relying on the assumption that the particle is dry at the point of deliquescence. However, this assumption does not hold for crystalline sodium chloride, which adsorbs several monolayers of water prior to the onset of deliquescence. "Predeliquescent" water adsorption is considered a significant effect especially for particles smaller than $400 \mathrm{~nm}$. Russell and Ming (2002, p. 311 and references therein) argued that "for deliquescence points at higher relative humidities, the Gibbs free energy of the phase change should be predicted by difference of the dissolved particle compared to the wetted particle rather than to the dry crystal. The difficulty of this approach is that it requires describing the free energy of the adsorbed water layer and its interface, since the surface energy of a thin adsorbed layer on a crystal of unknown geometry is poorly constrained." As a further challenge, Russell and Ming (2002) stated the adequate description of the surface energy of the interior and exterior interfaces of the spherical shell of water enveloping the dry crystal. The authors quantified the potential impact of variation of surface tension for finite-molecule situations by consideration of sizedependent surface tension using a simple Tolman length model. The generalised theoretical approach proposed in the present study considers the physical requirements formulated by Russell and Ming (2002). In their Figs. 4, 5, and 10-12, Russell and Ming (2002) presented predicted hygroscopic growth factors of nanometric $\mathrm{NaCl}$ particles for their "coated" and "uncoated" deliquescence models, which at first glance differ from our predictions depicted in Figs. 7 and 9. Depending on the chosen model, Russell and Ming (2002, Fig. 4 for $15 \mathrm{~nm}$ dry diameter $\mathrm{NaCl}$ ) distinguished several equilibrium regimes. For their "coated particle model" the authors found stable and metastable equilibria for the wet particle, stable, and unstable equilibria for the dry particle, unstable equilibria for partially wet particles, and deliquescence. For the "uncoated particle model", the only difference in predicted equilibria is the onset of deliquescence at a lower relative humidity. Despite the differences in the theoretical approaches and in the determination of the thermophysical properties, both approaches, i.e. that of Russell and Ming (2002) and the present one, describe the essential physical features of deliquescence of nanometric sodium chloride particles 
in agreement with available empirical findings. However, there are remarkable differences in the description of the heterogeneous nucleation pathway, i.e. in the hygroscopic growth of the partially wet particle. As the disjoining pressure is a continuous function of the film thickness, the predicted hygroscopic growth of the heterogeneous particle as shown in Figs. 7 and 9 reveals a smooth transition from the dry particle to the deliquescent point (stable equilibrium) and from the deliquescent point to the efflorescence point (conditionally stable equilibrium). In the approach of Russell and Ming (2002) these transitions show a more step-like behaviour. As the results of Russell and Ming (2002) and the ones presented here are both based on theoretical predictions, it is not possible to draw final conclusions regarding the predictive power of the employed theories with respect to the transitional behaviour in the heterogeneous regime. Nevertheless, both approaches appear to be reconcilable with available empirical findings on the hygroscopic growth of nanometric sodium chloride particles, i.e. available laboratory data cannot rule out either prediction so far.

6. The humidification of sodium chloride particles in the initial hydration stages is very sensitive to the specification of the disjoining pressure. While the overall shape of the humidity growth factor dependence on humidity does not change, the onset of water uptake strongly depends on the disjoining pressure scale, which has been parameterised in terms of the spreading coefficient and the correlation length scale. The enhancement of the wettability of the particle surface leads to an earlier onset of hygroscopic growth. However, it remains to be investigated how an explicit consideration of the dependence of the solution surface tension on the solution concentration in the theory will quantitatively affect the prediction of the humidity growth factor ${ }^{11}$. Also, a systematic sensitivity study using "alternative" formulations of the disjoining pressure remains to be done.

7. The calculations performed here give a theoretical explanation of the hysteresis effect during hydration/dehydration of a hygroscopic particle originating from the onset of the deliquescence and efflorescence transitions at different ambient humidities. Such hysteresis brings some "memory effect" into atmospheric phase transitions and was previously shown to affect aerosol-induced radiative forcing.

\footnotetext{
${ }^{11}$ It should be noted that the solution surface tension in the final equations cannot be a posteriori replaced by its concentrationdependent counterpart. Instead, the concentration-dependence of the surface tension must be already considered in the physical formulation of the chemical potentials and the energy balance itself. Moreover, the dependence of surface tension on concentration requires a consistent concentration dependent disjoining pressure.
}

8. The retrieval of physically meaningful values of the solution/solute interface energy and the correlation length for a tiny $\mathrm{NaCl}$ particle with a dry particle radius of $5 \mathrm{~nm}$ from experimentally determined ERH/DRH values required the consideration of the "nonideality" of the film solution. The employment of the "ideal solution" limit of the solvent and solute activities did not result in physically sound numerical solutions of the calculus, regardless of the use of alternative, physically possible interfacial parameters (according to parameter uncertainties).

\section{Remaining questions}

In order to demonstrate the feasibility of combined thermodynamic theory and CNT to describe memory effects during humidification/dehumidification of soluble nanoparticles, the present approach had to be restricted to a special, well-characterised aqueous inorganic-salt solution under such thermohumid conditions, for which preferably all of the required thermophysical properties were available from authoritative sources. For such a reference system the aqueous sodium chloride solution at $T=298 \mathrm{~K}$ has been chosen. However, even for this highly relevant and well-studied salt system there is still a great lack of quantitative insight into the properties of the $\mathrm{NaCl}$ surfaces such as the interfacial energy (see Sect. S.3.6 in the Supplement). Systematic simulations for the whole atmospheric temperature range, the full size range of nanoparticles, and other aqueous salt solutions, as well as discussion of application aspects, were beyond the scope of the current study. Nevertheless, owing to the practical relevance of these points we will add here some specific comments on remaining questions.

1. Temperature dependence of deliquescencelefflorescence: there is comprehensive phenomenological knowledge and theoretical analysis concerning the temperature dependence of both the deliquescence and efflorescence humidities (Khvorostyanov and Curry, 2014, Chapt. 11 therein). For example, for $\left(\mathrm{NH}_{4}\right)_{2} \mathrm{SO}_{4}$ Cziczo and Abbatt (1999, Fig. 6 therein) reported a negative temperature coefficient of the deliquescent humidity, $\mathrm{dDRH} / \mathrm{d} T<0$, in the temperature range $253-303 \mathrm{~K}$ with the following pairs of variates: $\mathrm{DRH}=(79.1 \pm 1) \% \mathrm{rh}$ at $T=298 \mathrm{~K}$; $(81 \pm 2) \%$ rh at $283 \mathrm{~K}$; $(82 \pm 2) \%$ rh at $273 \mathrm{~K}$ $(82 \pm 3) \%$ rh at $263 \mathrm{~K} ; \quad(83 \pm 4) \%$ rh at $254 \mathrm{~K}$. Similarly, the temperature coefficient of the efflorescence humidity was also found to be negative, $\mathrm{dERH} / \mathrm{d} T<0$, at least in the temperature range $253-298 \mathrm{~K}$ with the following pairs of variates: $\quad \mathrm{ERH}=(33 \pm 2) \% \mathrm{rh}$ at $T=298 \mathrm{~K}$; $(37 \pm 3) \%$ rh at $273 \mathrm{~K} ; \quad(42 \pm 4) \%$ rh at $253 \mathrm{~K}$; $(41 \pm 6) \%$ rh at $238 \mathrm{~K}$. A detailed theoretical evaluation of the temperature dependence of deliquescence and efflorescence and additional references can be 
found in Khvorostyanov and Curry (2014, Chapt. 11 therein).

The theory evaluated in the present paper does not contain any restrictions concerning the applicable temperature range. However, the challenge in the application of the model is the providence of the required experimentally determined thermophysical input properties in the extended temperature range, especially in the supercooled regime. For the surface tensions of pure water, aqueous sodium chloride, and ammonium-sulfate solutions there are appropriate correlation functions available (e.g. Seinfeld and Pandis, 2006, Sect. 17.1.3 therein; Kalová and Mares, 2012; Khvorostyanov and Curry, 2014, Sect. 4.4.5 therein). The temperature dependence of the solubility for different inorganic salts can be found in Seinfeld and Pandis (2006, Sect. 10.2.1 therein) without, however, explicit information on the allowed temperature range for application. Based on the Khvorostyanov-Curry (KC) model of deliquescent-heterogeneous freezing, Khvorostyanov and Curry (2014, Sect. 11.4.2, Eq. (11.4.9), Fig. 11.2 therein) derived a new equation for the temperature dependence of the solubility of inorganic salts. The authors demonstrated the applicability of this model to aqueous sodium chloride and ammonium-sulfate solutions in the temperature range $-40^{\circ} \mathrm{C} \leq \vartheta \leq 100^{\circ} \mathrm{C}$. In addition, the temperature dependence of the relative deviation of the $\mathrm{KC}$ model predictions from measured data has been quantified.

Similarly, Khvorostyanov and Curry (2014, Sect. 11.4.3, Fig. 11.3 therein) derived an expression for the temperature dependence of the water activity in the limiting case of an ideal solution. For an aqueous ammonium-sulfate solution, the authors found very good agreement of the $\mathrm{KC}$ predictions with measured water activities in the temperature range $240 \mathrm{~K} \leq T \leq 370 \mathrm{~K}$.

Importantly, the empirical characterisation and theoretical description of several water-salt systems published in previous studies such as those performed by Khvorostyanov and Curry (2014, Chapt. 11, Figs. 11.1-11.4, see also references therein) can be used as reference data for systematic model-to-model intercomparison studies.

In the limiting case of "thick" solution films (vanishing disjoining pressure), all simulations should agree for the same thermophysical input data. The main focus of the present model is on the description of thin-film systems, allowing the treatment of size effects of deliquescence and efflorescence, which are very important in the early stages of water uptake. Additional empirical and modelling data for the temperature-dependence of deliquescence and efflorescence in the limiting case of bulk systems can be used, e.g. to formulate additional mathematical constraints for the determination of hygroscopic and interface properties of ambient aerosol systems (see item 4). Further efforts in this direction should also aim at the demonstration that different theoretical approaches to solve identical questions of interest (the same chemical composition and size of the aerosol system under the same thermohumid conditions) are physically reconcilable and consistent among each other.

2. Thermophysical properties: the solute supersaturation, $S^{(\alpha)}=a_{\mathrm{s}, \text { effl }} / a_{\mathrm{s} \text {, sat }}$, defined as the ratio of the salt activity at efflorescence, $a_{\mathrm{s} \text {, effl }}$, to the saturated activity at deliquescence, $a_{\mathrm{s} \text {, sat }}$, has been reported to exceed values of 20-30 (depending on the inorganic salt) at the point of homogeneous efflorescence (Khvorostyanov and Curry, 2014, pp. 548, 551 therein). Such high values pose a great challenge regarding the molality range of experiments to determine the solution viscosity, which enters the calculus via the activation energy in the kinetic prefactor of the homogeneous efflorescence rate. For example, available table values for the viscosity of an aqueous sodium chloride solution are usually restricted to molalities not exceeding the saturation molality, $m \leq m_{\mathrm{s}, \mathrm{sat}}=6 \mathrm{~mol} \mathrm{~kg}{ }^{-1}$ (see Sect. S.3.5 in the Supplement). Hence, the application of these table values to highly supersaturated states, occurring at the point of homogeneous efflorescence, is necessarily based on extrapolation with unknown uncertainty.

In the present study, the determination of the solvent and solute activities is based on the Ally-Braunstein statistical mechanics theory of multilayer adsorption for highly concentrated solutions in combination with an empirical solvent activity as function of molality (see Sect. S.3.1 in the Supplement). For the solvent activity a molality dependence has been used, the validity of which is restricted to $T=298 \mathrm{~K}$. Hence, application of the calculus to the aqueous sodium chloride system at temperatures $T \neq 298 \mathrm{~K}$ requires corresponding revision of the solvent activity formula or at least quantification of the uncertainty of extrapolated activities and the associated model sensitivity.

For the solubility of the sodium chloride solute a temperature-dependent bulk value has been used (see Sect. S.3.4 in the Supplement). For the time being nothing conclusive can be said about a possible sizedependence of this quantity and the model sensitivity to such dependence.

Sources of experimental data and formulations of thermophysical properties for application of the theory to supercooled states down to the eutectic temperature are the IAPWS pool of thermophysical properties (http://www.iapws.org/), the new Thermodynamic Equation Of Seawater 2010 (TEOS-10, http://www. teos-10.org/), and the FREZCHEM database (http:// www.dri.edu/frezchem). 
3. Refinement of the theory: the current theory is based on the assumption that, among others, the vapour/solution surface tension is independent of the solution concentration. In reality, the surface tension of an aqueous solution depends on the solution molality (e.g. Seinfeld and Pandis, 2006, Sect. 17.1.3 therein; Khvorostyanov and Curry, 2014, Sect. 4.4.5 therein). The uncertainty originating from the neglect of the molality dependence of the solution surface tension is needed to be quantified. However, the consideration of the molality dependence of the surface tension requires a re-derivation of the whole calculus and will lead to the appearance of additional terms in the generalised thermodynamic equilibrium equations.

Another challenge is the generalisation of the theory to a multicomponent three-phase system, e.g. for application to describe formation of secondary organic aerosols in the film phase.

4. Other binary aqueous solutions of unary salts and organo-salt mixtures: the variety of atmospherically relevant aerosols containing either pure inorganic salts or mixtures of inorganic salts with organic compounds is very large, whereas mixed states of hygroscopic particles have to be considered as the atmospheric normal case. In light of the high importance of water uptake by such systems for cloud droplet activation, there are multitudinous studies on the deliquescence and efflorescence (e.g. Cziczo and Abbatt, 1999; Xu et al., 1998; Oatis et al., 1998; Khvorostyanov and Curry, 2014) and hygroscopic growth of "pure" and "mixed" particle systems (e.g. Michel Flores et al., 2012; Sjogren et al., 2007; Stock et al., 2011).

The present theory allows the simulation of water adsorption of unary salts from the first monolayer and the reverse process - water desorption until homogeneous efflorescence - provided the required thermophysical properties and interface parameters are available. As emphasised previously, a special challenge is the determination of the disjoining pressure. Employing measured DRH and ERH values, it was demonstrated here how these interface parameters can be estimated.

With retainment of the basic assumptions of the present theory, this monocomponent approach can be extended to mixed hygroscopic particles by consideration of the Zdanovskii-Stokes-Robinson (ZSR) relation for the growth factor of mixtures (e.g. Michel Flores et al., 2012, Sjogren et al., 2007, Stokes and Robinson, 1966, Stock et al., 2011), which provides an additional constraint for the estimation of interface parameters for mixed particles within the framework of the present approach. The combination of the current theory with the ZSR relation opens a semi-empirical way to derive interface parameters for atmospherically relevant mixed aerosol systems from both measured volume fractions of the pure components in the mixture (e.g. using an aerosol mass spectrometer) and hygroscopic growth factors of these mixed systems (using a hygroscopic tandem differential mobility analyser) (personal communication with L. Poulain, TROPOS Leipzig, December 19, 2014). In turn, provided that the relevant interface properties are available with sufficient accuracy, the present model can be used to predict the size- and temperaturedependent hygroscopic growth factors of mixed particles.

5. Application in aerosol-dynamical and microphysical models: provided all necessary thermophysical and interfacial properties of the chemical substances of interest can be acquired, the application of the present calculus in a bin-resolved aerosol-dynamical or microphysical model requires (a) the implementation of an efficient numerical solver for the solution of the coupled transcendental equations describing the humidity growth factor and the chemical composition of the aerosol system as function of both temperature and relative humidity or, alternatively, (b) the precalculation of look-up tables with the corresponding values (eventually complemented by an effective interpolation routine).

In order to decide which of the multiple (and equitable) thermodynamic states (size and composition) a certain particle will adopt under specific thermohumid conditions during its lifetime, one must know not only the actual temperature and humidity but also their history, i.e. the "memory" of the aerosol system must be carried along the simulation, notwithstanding that only equilibrium states are considered. In context with the specification of the time resolution of a host model which incorporates the calculus, an analysis of the characteristic time scales to establish the Gibbs-Kelvin-Köhler and Ostwald-Freundlich equilibria for the specific systems of interest is required.

\section{The Supplement related to this article is available online at doi:10.5194/acp-15-3851-2015-supplement.}

Acknowledgements. The contribution of O. Hellmuth was provided within the framework of the research theme 1 "Aerosols - Process studies at small temporal and spatial scales" of the Leibniz Institute for Tropospheric Research (TROPOS), Leipzig. A. K. Shchekin thanks for St. Petersburg State University grants 11.0.59.2010 and 11.37.183.2014. Many thanks are given to Vitaly Khvorostyanov for discussions on ice and salt crystallisation in eutectic systems and to Moonis Ally for discussions on the Ally-Braunstein theory of multilayer adsorption of water on salt particles. The authors also thank the anonymous referees and the editor Tuukka Petäjä for their helpful comments to improve the manuscript. Finally, we thank Arielle Maler for careful copy-editing changes and Frauke Jurgeleit 
and her colleagues for typesetting of the manuscript in the different processing stages.

Edited by: T. Petäjä

\section{References}

Ally, M. R. and Braunstein, J.: Statistical mechanics of multilayer adsorption: electrolyte and water activities in concentrated solutions, J. Chem. Thermodyn., 30, 49-58, 1998.

Anonymous Referee: Interactive comment (RC C9360) on "Determination of interfacial parameters of a soluble particle in a nonideal solution from measured deliquescence and efflorescence humidities" by O. Hellmuth and A. K. Shchekin, Atmos. Chem. Phys. Discuss., 14, C9360-C9364, 2014.

Atkins, P. W.: Physical Chemistry. Fifth Edition, Oxford University Press, Oxford, ISBN 0-19-855730-2 (Pbk), 1031 pp., 1994.

Biskos, G., Malinowski, A., Russell, L. M., Buseck, P. R., and Martin, S. T.: Nanosize effect on the deliquescence and the efflorescence of sodium chloride particles, Aerosol Sci. Tech., 40, 97106, doi:10.1080/02786820500484396, 2006a.

Biskos, G., Paulsen, D., Russell, L. M., Buseck, P. R., and Martin, S. T.: Prompt deliquescence and efflorescence of aerosol nanoparticles, Atmos. Chem. Phys., 6, 4633-4642, doi:10.5194/acp-6-4633-2006, 2006b.

Bontjer, A.: Kochsalz. Chemie, Eigenschaften und Bedeutung, Vortrag, Phillips-Universität Marburg, Fachbereich Chemie, 12 January 2006, available at: http://www.chids.de/veranstaltungen/ uebungen_experimentalvortrag.html (last access: 6 February 2015), presentation number 700, 2014.

Brdička, R.: Grundlagen der physikalischen Chemie. 5., ergänzte und überarbeitete Auflage, VEB Deutscher Verlag der Wissenschaften, Berlin, Lizenz-Nr. 206 • 435/55/65, 1965.

Bruzewicz, D. A., Checco, A., Ocko, B. M., Lewis, E. R., McGraw, R. L., and Schwartz, S. E.: Reversible uptake of water on $\mathrm{NaCl}$ nanoparticles at relative humidity below deliquescence point observed by noncontact environmental atomic force microscopy, J. Chem. Phys., 134, 044702, doi:10.1063/1.3524195, 2011.

Cziczo, D. and Abbatt, J. D.: Deliquescence, efflorescence, and supercooling of ammonium sulfate aerosols at low temperature: implications for cirrus cloud formation and aerosol phase in the atmosphere, J. Geophys. Res., 104, 13781-13790, 1999.

Curry, J. A. and Khvorostyanov, V. I.: Assessment of some parameterizations of heterogeneous ice nucleation in cloud and climate models, Atmos. Chem. Phys., 12, 1151-1172, doi:10.5194/acp12-1151-2012, 2012.

Derjaguin, B. V.: The definition and magnitude of disjoining pressure and its role in the statics and dynamics of thin fluid films, Kolloid Zh., 17, 207-214, 1955a.

Derjaguin, B. V.: Definition of the concept and the magnitude of the disjoining pressure and its role in the statics and kinetics of thin layers of liquids, Colloid Journal USSR, 17, 191-197, 1955b.

Derjaguin, B. V., Churaev, N. V., and Muller, V. M.: Surface Forces, Consultants Bureau, New York, 1987.

Djikaev, Y. S.: Kinetics of fluctuational deliquescence, J. Chem. Phys., 116, 9865-9874, doi:10.1063/1.1475743, 2002.
Djikaev, Y. S., Bowles, R., and Reiss, H.: Role of constraints in the thermodynamics of heterogeneous condensation on solid soluble particles: failure of the capillarity approximation, Physica A, 298, 155-176, 2001a.

Djikaev, Y. S., Bowles, R., Reiss, H., Hämeri, K., Laaksonen, A., and Väkevä, M.: Theory of size dependent deliquescence of nanoparticles: relation to heterogeneous nucleation and comparison with experiments, J. Phys. Chem. B, 105, 7708-7722, doi:10.1021/jp010537e, 2001b.

Gao, Y., Chen, S. B., and Yu, L. E.: Efflorescence relative humidity of airborne sodium chloride particles: a theoretical investigation, Atmos. Environ., 41, 2019-2023, doi:10.1016/j.atmosenv.2006.12.014, 2007.

Hämeri, K., Laaksonen, A., Väkevä, M., and Suni, T.: Hygroscopic growth of ultrafine sodium chloride particles, J. Geophys. Res., 106, 20749-20757, 2001.

Kalová, J. and Mares, R.: Second inflection point of the surface tension of water, Int. J. Thermophys., 33, 992-999, 2012.

Khvorostyanov, V. I. and Curry, J. A.: A new theory of heterogeneous ice nucleation for application in cloud and climate models, Geophys. Res. Lett., 27, 4081-4084, 2000.

Khvorostyanov, V. I. and Curry, J. A.: Thermodynamic theory of freezing and melting of water and aqueous solutions, J. Phys. Chem. A, 108, 11073-11085, doi:10.1021/jp048099, 2004a.

Khvorostyanov, V. I. and Curry, J. A.: The theory of ice nucleation by heterogeneous freezing of deliquescent mixed CCN. Part I: Critical radius, energy, and nucleation rate, J. Atmos. Sci., 61, 2676-2691, 2004b.

Khvorostyanov, V. I. and Curry, J. A.: The theory of ice nucleation by heterogeneous freezing of deliquescent mixed CCN. Part II: Parcel model simulation, J. Atmos. Sci., 62, 261-285, 2005.

Khvorostyanov, V. I. and Curry, J. A.: Refinements to the Köhler's theory of aerosol equilibrium radii, size spectra, and droplet activation: effects of humidity and insoluble fraction, J. Geophys. Res., 112, D05206, doi:10.1029/2006JD007672, 2007.

Khvorostyanov, V. I. and Curry, J. A.: Critical humidities of homogeneous and heterogeneous ice nucleation: inferences from extended classical nucleation theory, J. Geophys. Res., 114, D04307, doi:10.1029/2008JD011197, 2009.

Khvorostyanov, V. I. and Curry, J. A.: Parameterization of homogeneous ice nucleation for cloud and climate models based on classical nucleation theory, Atmos. Chem. Phys., 12, 9275-9302, doi:10.5194/acp-12-9275-2012, 2012.

Khvorostyanov, V. I. and Curry, J. A.: Thermodynamics, Kinetics, and Microphysics of Clouds, Cambridge University Press, ISBN 978-1-107-01603-3, 782 pp., first edn., 2014.

Khvorostyanov, V. I. and Sassen, K.: Cirrus cloud simulation using explicit microphysics and radiation. Part I: model description, J. Atmos. Sci., 55, 1808-1821, 1998a.

Khvorostyanov, V. I. and Sassen, K.: Toward the theory of homogeneous ice nucleation and its parameterization for cloud models, Geophys. Res. Lett., 25, 3155-3158, 1998b.

Khvorostyanov, V. I. and Sassen, K.: Microphysical processes in cirrus and their impact on radiation: a mesoscale modeling perspective, in: Cirrus, edited by Lynch, D. K., Sassen, K., Starr, D. O., and Stephens, G., Oxford University Press, Oxford, chap. 19, 397-432, 2002.

Khvorostyanov, V. I., Curry, J. A., Pinto, J. O., Shupe, M., Baker, B. A., and Sassen, K.: Modeling with explicit spectral wa- 
ter and ice microphysics of a two-layer cloud system of altostratus and cirrus observed during FIRE Arctic Clouds Experiment, J. Geophys. Res., 106, 15099-15112, 2001.

Khvorostyanov, V. I., Curry, J. A., Gultepe, I., and Strawbridge, K.: A springtime cloud over the Beaufort Sea polynya: threedimensional simulation with explicit spectral microphysics and comparison with observations, J. Geophys. Res., 108, 4296, doi:10.1029/2001JD001489, 2003.

Khvorostyanov, V. I., Morrison, H., Curry, J. A., Baumgardner, D., and Lawson, P.: High supersaturation and modes of ice nucleation in thin tropopause cirrus: simulation of the 13 July 2002 Cirrus Regional Study of Tropical Anvils and Cirrus Layers case, J. Geophys. Res., 111, D02201, doi:10.1029/2004JD005235, 2006.

Kuni, F. M., Shchekin, A. K., Rusanov, A. I., and Widom, B.: Role of surface forces in heterogeneous nucleation on wettable nuclei, Adv. Colloid Interfac., 65, 71-124, 1996.

Kuni, F. M., Shchekin, A. K., and Grinin, A. P.: Theory of heterogeneous nucleation for vapour undergoing a gradual metastable state formation process, Physics Uspekhi, 44, 331-370, 2001.

Li, B.: Density-Functional Theory and Quantum Chemistry Studies on "dry" and "wet" $\mathrm{NaCl}(001)$, Ph.D. thesis, Technical University of Berlin, Faculty of Mathematics and Natural Sciences, Berlin, 2009.

Liu, W. T., Tang, W., and Niler, P. P.: Humidity profiles over the ocean, J. Climate, 4, 1023-1034, 1991.

Lohmann, U. and Feichter, J.: Global indirect aerosol effects: a review, Atmos. Chem. Phys., 5, 715-737, doi:10.5194/acp-5-7152005, 2005.

Marčelja, S. and Radić, N.: Repulsion of interfaces due to boundary water, Chem. Phys. Lett., 42, 129-130, 1976.

McGraw, R. and Lewis, E.: Deliquescence and efflorescence of small particles, J. Chem. Phys., 131, 194705, doi:10.1063/1.3251056, 2009.

Michel Flores, J., Bar-Or, R. Z., Bluvshtein, N., Abo-Riziq, A., Kostinski, A., Borrmann, S., and Koren, I.: Absorbing aerosols at high relative humidity: linking hygroscopic growth to optical properties, Atmos. Chem. Phys., 12, 5511-5521, doi:10.5194/acp-12-5511-2012, 2012.

Mirabel, P., Reiss, H., and Bowles, R. K.: A theory for the deliquescence of small particles, J. Chem. Phys., 113, 8200, doi:10.1063/1.1315993, 2000.

Oatis, S., Imre, D., McGraw, R., and Xu, J.: Heterogeneous nucleation of a common atmospheric aerosol: ammonium sulfate, Geophys. Res. Lett., 25, 4469-4472, 1998.

Onasch, T. B., McGraw, R., and Imre, D.: Temperaturedependent heterogeneous efflorescence of mixed ammonium sulfate/calcium carbonate particles, J. Phys. Chem. A, 104, 1079710806, doi:10.1021/jp0024064, 2000.

Pant, A., Parsons, M. T., and Bertram, A. K.: Crystallization of aqueous ammonium sulfate particles internally mixed with soot and kaolinite: crystallization relative humidites and nucleation rates, J. Phys. Chem. A, 110, 8701-8709, doi:10.1021/jp060985s, 2006.

Parsons, M. T., Riffell, J. L., and Bertram, A. K.: Crystallization of aqueous inorganic-malonic acid particles: nucleation rates, dependence on size, and dependence on the ammonium-to-sulfate ratio, J. Phys. Chem. A, 110, 8108-8115, doi:10.1021/jp057074n, 2006.
Romakkaniemi, S., Hämeri, K., Väkevä, M., and Laaksonen, A.: Adsorption of water on $8-15 \mathrm{~nm} \mathrm{NaCl}$ and $\left(\mathrm{NH}_{4}\right)_{2} \mathrm{SO}_{4}$ aerosols measured using an ultrafine tandem differential mobility analyzer, J. Phys. Chem. A, 105, 8183-8188, doi:10.1021/jp0106471, 2001.

Rusanov, A. I., Kuni, F. M., and Shchekin, A. K.: On the thermodynamics of thin wetting films, Colloid J. Russ. Acad.+, 56, 172173, 1994.

Russell, L. M. and Ming, Y.: Deliquescence of small particles, J. Chem. Phys., 116, 311-321, doi:10.1063/1.1420727, 2002.

Schmiedel, H.: Rund ums Salz - mit Tips und Rezepten, VEB Fachbuchverlag Leipzig, Leipzig, 183 pp., 1984.

Seinfeld, J. H. and Pandis, S. N.: Atmospheric Chemistry and Physics. From Air Pollution to Climate Change, John Wiley \& Sons Inc., New York, 1225 pp., 2006.

Shchekin, A. K. and Rusanov, A. I.: Generalization of the GibbsKelvin-Köhler and Ostwald-Freundlich equations for a liquid film on a soluble nanoparticle, J. Chem. Phys., 129, 154116, doi:10.1063/1.2996590, 2008.

Shchekin, A. K. and Shabaev, I. V.: Thermodynamics and kinetics of deliquescence of small soluble particles, in: Nucleation Theory and Applications, edited by: Schmelzer, J. W. P., Röpke, G., and Priezzhev, V. B., JINR Joint Institute for Nuclear Research, Bogoliubov Laboratory of Theoretical Physics, Dubna, 267-291, 2005.

Shchekin, A. K. and Shabaev, I. V.: Activation barriers for the complete dissolution of condensation nucleus and its reverse crystallization in droplets in the undersaturated solvent vapor, Colloid J., 72, 432-439, doi:10.1134/S1061933X1003018X, 2010.

Shchekin, A. K., Rusanov, A. I., and Kuni, F. M.: Thermodynamics of condensation on soluble nuclei of colloidal surfactants, Colloid J. Russ. Acad., 55, 227-234, 1993.

Shchekin, A. K., Shabaev, I. V., and Rusanov, A. I.: Thermodynamics of droplet formation around a soluble condensation nucleus in the atmosphere of a solvent vapor, J. Chem. Phys., 129, 214111, doi:10.1063/1.3021078, 2008.

Shchekin, A. K., Shabaev, I. V., and Hellmuth, O.: Thermodynamic and kinetic theory of nucleation, deliquescence and efflorescence transitions in the ensemble of droplets on soluble particles, J. Chem. Phys., 138, 054704, doi:10.1063/1.4789309, 2013.

Sjogren, S., Gysel, M., Weingartner, E., Baltensperger, U., Cubison, M. J., Coe, H., Zardini, A. A., Marcolli, C., Krieger, U. K., and Peter, T.: Hygroscopic growth and water uptake kinetics of two-phase aerosol particles consisting of ammonium sulfate, adipic and humic acid mixtures, J. Aerosol Sci., 38, 157-171, doi:10.1016/j.jaerosci.2006.11.005, 2007.

Stock, M., Cheng, Y. F., Birmili, W., Massling, A., Wehner, B., Müller, T., Leinert, S., Kalivitis, N., Mihalopoulos, N., and Wiedensohler, A.: Hygroscopic properties of atmospheric aerosol particles over the Eastern Mediterranean: implications for regional direct radiative forcing under clean and polluted conditions, Atmos. Chem. Phys., 11, 4251-4271, doi:10.5194/acp11-4251-2011, 2011.

Stokes, R. H. and Robinson, R. A.: Interactions in aqueous nonelectrolyte solutions. I. Solute-solvent equilibria, J. Phys. Chem., 70, 2126-2130, 1966.

Wagner, R. and Möhler, O.: Heterogeneous ice nucleation ability of crystalline sodium chloride dihydrate particles, J. Geophys. Res., 118, 4610-4622, doi:10.1002/jgrd.50325, 2013. 
Wang, J., Hoffmann, A. A., Park, R. J., Jacob, D. J., and Martin, S. T.: Global distribution of solid and aqueous sulfate aerosols: effect of the hysteresis of particle phase transitions, J. Geophys. Res., 113, D11206, doi:10.1029/2007JD009367, 2008a.

Wang, J., Jacob, D. J., and Martin, S. T.: Sensitivity of sulfate direct climate forcing to the hysteresis of particle phase transitions, J. Geophys. Res., 113, D11207, doi:10.1029/2007JD009368, 2008 b.

Wedler, G.: Lehrbuch der Physikalischen Chemie, Wiley-VCH Verlag GmbH \& Co. KGaA, Weinheim, ISBN 3-527-31066-5, 1072 pp., 2004.
Wise, M. E., Baustian, K. J., Koop, T., Freedman, M. A., Jensen, E. J., and Tolbert, M. A.: Depositional ice nucleation onto crystalline hydrated $\mathrm{NaCl}$ particles: a new mechanism for ice formation in the troposphere, Atmos. Chem. Phys., 12, 1121-1134, doi:10.5194/acp-12-1121-2012, 2012.

Wolf, K. L.: Theoretische Chemie. Eine Einführung vom Standpunkt einer gestalthaften Atomlehre. Vierte, umgearbeitete Auflage, Johann Ambrosius Barth Verlag Leipzig, Lizenz-Nr. 285/125/61/59, 1959.

Xu, J., Imre, D., McGraw, R., and Tang, I.: Ammonium sulfate: equilibrium and metastability phase diagrams from 40 to $-50^{\circ} \mathrm{C}$, J. Phys. Chem. B, 102, 7462-7469, 1998. 